\title{
A European perspective on alternatives to animal testing for environmental hazard identification and risk assessment
}

Stefan Scholz ${ }^{\mathrm{a}, *}$, Erika Sela ${ }^{\mathrm{b}}$, Ludek Blaha ${ }^{\mathrm{c}, 1}$, Thomas Braunbeck ${ }^{\mathrm{d}, 2}$, Malyka Galay-Burgos ${ }^{\mathrm{e}, 3}$, Mauricio García-Franco $^{\text {b,4 }}{ }^{\text {, Joaquin Guinea }}{ }^{\text {, }}$, Nils Klüver ${ }^{\mathrm{a}, 5}$, Kristin Schirmer ${ }^{\text {f,g,h,6 }}$, Katrin Tanneberger ${ }^{\mathrm{f}, 6}$, Marysia Tobor-Kapłon $^{\mathrm{i}}$, Hilda Witters ${ }^{\mathrm{j}, 7}$, Scott Belanger ${ }^{\mathrm{k}, 8}$, Emilio Benfenati ${ }^{1,9}$, Stuart Creton $^{\mathrm{m}, 10}$, Mark T.D. Cronin ${ }^{\mathrm{n}, 11}$, Rik I.L. Eggen ${ }^{\mathrm{o}, \mathrm{h}, 12}$, Michelle Embry ${ }^{\mathrm{p}, 13}$, Drew Ekman ${ }^{\mathrm{q}}$, Anne Gourmelon ${ }^{\mathrm{r}}$, Marlies Halder ${ }^{\mathrm{s}, 14}$, Barry Hardy ${ }^{\mathrm{t}}$, Thomas Hartung ${ }^{\mathrm{u}, 15}$, Bruno Hubesch ${ }^{\mathrm{v}, 16}$, Dirk Jungmann ${ }^{\mathrm{w}, 17}$, Mark A. Lampi ${ }^{\mathrm{x}, 18}$, Lucy Lee ${ }^{\mathrm{y}, 19}$, Marc Léonard ${ }^{\mathrm{z}, 20}$, Eberhard Küster ${ }^{\mathrm{a}, 5}$, Adam Lillicrap ${ }^{\text {aa,21, }}$, Till Luckenbach ${ }^{\mathrm{a}, 5}$, Albertinka J. Murk ${ }^{\mathrm{ab}}$, José M. Navas ${ }^{\mathrm{ac}, 22}$, Willie Peijnenburg ad,ae,23,

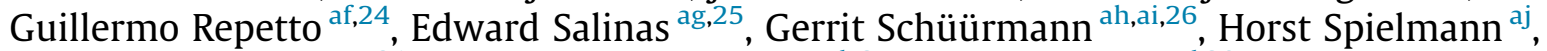

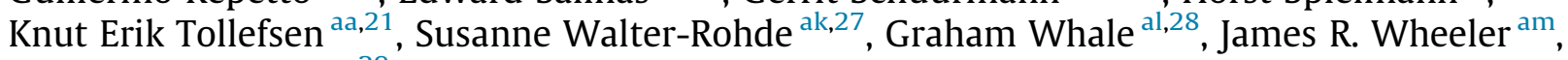
Matthew J. Winter ${ }^{\text {an, } 29}$

\footnotetext{
* Corresponding author. Fax: +49 3412351787. com (J.R. Wheeler), matthew.winter@astrazeneca.com (M.J. Winter).

${ }^{1}$ Fax: +420 549492840 .

2 Fax: $+49(0) 6221546162$.

${ }^{3}$ Fax: +32 26753625 .

${ }^{4}$ Present address: AQUACRIA C.A.C/Albeniz, 20 (Urb. El Mirador)Valdetorres del Jarama. 24150 (Madrid) Spain. Tel.: +34-617740501.

5 Fax: +493412351787.

${ }^{6}$ Fax: +41 448235311 .

7 Fax: +32 14582657

8 Fax: +1 5132778356 .

9 Fax: +390239014735 .

${ }^{10}$ Current address: Environmental Protection Authority, 215 Lambton Quay, Wellington 6140, New Zealand.

${ }^{11}$ Fax: +441512312170.

12 Fax: +41 (0)58 7655898

${ }^{13}$ Fax: +1 2026593617 .

14 Fax: +390332 786297

${ }^{15}$ Fax: +1 4106142871

${ }^{16}$ Fax: +3226767392

17 Fax: +4935146337108

18 Fax: +32 (0)2 7224228 .

19 Fax: +1 6048596653 .

${ }^{20}$ Fax: +3314868 8927 .

${ }^{21}$ Fax: +4722185200 .

${ }^{22}$ Fax: +34 913572293

${ }^{23}$ Fax: +31 302744413.

24 Fax: +34954349813.

${ }^{25}$ Fax: +496216058043 .

${ }^{26}$ Fax: +49 3412351785 .

${ }^{27}$ Fax: +49 34021042330

28 Fax: +4401513735406

${ }^{29}$ Fax: +44 1803882974 .
}

E-mail addresses: stefan.scholz@ufz.de (S. Scholz), esela@zfbiolabs.com (E. Sela), blaha@recetox.muni.cz (L. Blaha), braunbeck@uni-hd.de (T. Braunbeck), malyka.galayburgos@ecetoc.org (M. Galay-Burgos), mgarcia@zfbiolabs.com, mauricio.garciafranco@gmail.com, mauricio.gf@aquacria.com (M. García-Franco), jguinea@zfbiolabs.com (J. Guinea),nils.kluever@ufz.de (N. Klüver), kristin.schirmer@eawag.ch (K. Schirmer), marysia.tobor-kaplon@wilresearch.com (M. Tobor-Kapłon), hilda.witters@vito.be (H. Witters), belanger.se@pg.com (S. Belanger), benfenati@marionegri.it (E. Benfenati), stuart.creton@nc3rs.org.uk, stuart.creton@epa.govt.nz (S. Creton), m.t.cronin@ljmu. ac.uk (M.T.D. Cronin), rik.eggen@eawag.ch (R.I.L. Eggen), membry@ilsi.org (M. Embry), ekman.drew@epa.gov (D. Ekman), anne.gourmelon@oecd.org (A. Gourmelon), marlies.halder@ec.europa.eu (M. Halder), barry.hardy@douglasconnect.com (B. Hardy), thartung@jhsph.edu (T. Hartung), bhu@cefic.be (B. Hubesch), dirk.jungmann@tudresden.de (D. Jungmann), mark.a.lampi@exxonmobil.com (M.A. Lampi), lucy.lee@ufv.ca (L. Lee), mleonard@rd.loreal.com (M. Léonard), eberhard.kuester@ufz.de (E. Küster), adam.lillicrap@niva.no (A. Lillicrap), till.luckenbach@ufz.de (T. Luckenbach), tinka.murk@wur.nl (A.J. Murk), jmnavas@inia.es (J.M. Navas), willie.peijnenburg@rivm.nl (W. Peijnenburg), grepkuh@upo.es (G. Repetto), edward.salinas@basf.com (E. Salinas), gerrit.schuurmann@ufz.de (G. Schüürmann), horst.spielmann@fu-berlin.de (H. Spielmann), knut.erik.tollefsen@niva.no (K.E. Tollefsen), susanne.walter-rohde@uba.de (S. Walter-Rohde), graham.whale@shell.com (G. Whale), james.wheeler@syngenta. 
a UFZ - Helmholtz Centre for Environmental Research, Department of Bioanalytical Ecotoxicology, 04318 Leipzig, Germany

b ZF Biolabs, Ronda de Valdecarrizo 41B, Bajo, 28760 Tres Cantos (Madrid), Spain

${ }^{\mathrm{c}}$ Masaryk University, Faculty of Science RECETOX (Research Centre for Toxic Compounds in the Environment), Kamenice 753/5, Pavilion A29, 625 00 Brno, Czech Republic

${ }^{\mathrm{d}}$ Aquatic Ecology \&' Toxicology, COS - Center for Organismal Studies, University of Heidelberg, Im Neuenheimer Feld 230, 69120 Heidelberg, Germany

e ECETOC (European Centre for Ecotoxicology and Toxicology of Chemicals), Avenue E. Van Nieuwenhuyse Building 2, 3rd Floor, Bte 81160 Brussels, Belgium

${ }^{\mathrm{f}}$ Eawag, Swiss Federal Institute of Aquatic Science and Technology, Department Environmental Toxicology, Überlandstrasse 133, P.O. Box 611, 8600 Dübendorf, Switzerland

${ }^{g}$ EPF Lausanne, School of Architecture, Civil and Environmental Engineering, 1015 Lausanne, Switzerland

${ }^{\text {h }}$ ETH Zürich, Department of Environmental Systems Science, 8092 Zürich, Switzerland

${ }^{\mathrm{i}}$ WIL Research Europe B.V., Hambakenwetering 7, 5231 DD ‘s-Hertogenbosch, The Netherlands

${ }^{\mathrm{j}}$ Flemish Institute for Technological Research (Vito), Environmental Risk E Health, Team Applied Bio E Molecular Systems (ABS) Boeretang 200, Mol 2400, Belgium

${ }^{\mathrm{k}}$ The Procter \& Gamble Company, Global Product Stewardship, 8700 Mason Montgomery Road, Mason, OH 45040, United States

${ }^{1}$ IRCCS - Istituto di Ricerche Farmacologiche, “Mario Negri” Laboratory of Environmental Chemistry and Toxicology, Via La Masa 19, 20156 Milano, Italy

${ }^{\mathrm{m}}$ National Centre for the Replacement, Refinement and Reduction of Animals in Research (NC3Rs), Gibbs Building, 215 Euston Road, London NW1 2BE, United Kingdom

${ }^{\mathrm{n}}$ Liverpool John Moores University, School of Pharmacy and Biomolecular Sciences, Byrom Street, Liverpool L3 3AF, United Kingdom

${ }^{\circ}$ Eawag, Swiss Federal Institute of Aquatic Science and Technology, Überlandstrasse 133, P.O. Box 611, 8600 Dübendorf, Switzerland

${ }^{\mathrm{p}}$ ILSI Health and Environmental Sciences Institute (HESI), 1156 15th Street, NW, 2nd floor, Washington, DC 20005, United States

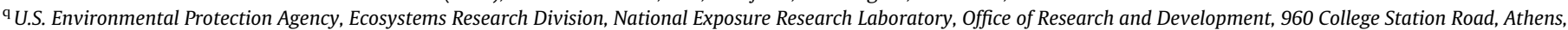
GA 30605-2700, United States

${ }^{\mathrm{r}}$ Organisation for Economic Co-operation and Development (OECD), 2 Rue André Pascal, 75016 Paris, France

${ }^{\mathrm{s}}$ European Commission Joint Research Centre, Institute for Health and Consumer Protection, EURL ECVAM, Via E. Fermi 2749,21027 Ispra (Varese), Italy

${ }^{\mathrm{t}}$ Douglas Connect, Bärmeggenweg 14, 4314 Zeiningen, Switzerland

u Johns Hopkins University, Bloomberg School of Public Health, CAAT, 615 N. Wolfe Street, Baltimore, MD 21205, United States

${ }^{v}$ CEFIC - The European Chemical Industry Council, 4 Avenue E. Van Nieuwenhuyse, 1160 Brussels, Belgium

${ }^{\mathrm{w}}$ Technische Universität Dresden, Fakultät Umweltwissenschaften, Institut für Hydrobiologie,01062 Dresden, Germany

${ }^{x}$ ExxonMobil Petroleum and Chemical, Hermeslaan 2, 1831 Machelen, Belgium

${ }^{\mathrm{y}}$ Department of Biology, University of the Fraser Valley, Abbotsford, BC, Canada

${ }^{\mathrm{z}}$ L'ORÉAL Research and Innovation, Environmental Research Department, 1 Avenue Eugène Schueller, 93601 Aulnay sous Bois, France

${ }^{\text {aa }}$ Norwegian Institute for Water Research (NIVA), Gaustadalléen 21, 0349 Oslo, Norway

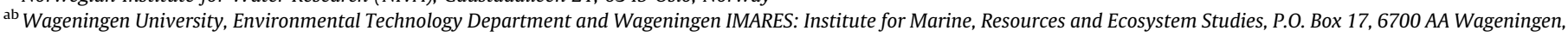
The Netherlands

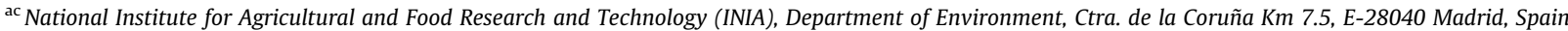

${ }^{\text {ad }}$ RIVM, Center for Substances and Products, P.O. Box 1, 3720 BA Bilthoven, The Netherlands

ae Univerisity of Leiden, Center for Environmental Sciences (CML), Leiden, The Netherlands

af University Pablo de Olavide, Area of Toxicology, Dep. Biologia Molecular e Ingeniería, Bioquímica, Ctra. de Utrera Km 1, 41013 Sevilla, Spain

${ }^{\mathrm{ag}}$ Experimental Toxicology and Ecology (GV/TC), BASF SE, GV/TC - Z570, 67056 Ludwigshafen, Germany

${ }^{\text {ah }}$ UFZ - Helmholtz Centre for Environmental Research, Department of Ecological Chemistry, 04318 Leipzig, Germany

ai Institute for Organic Chemistry, Technical University Bergakademie Freiberg, Leipziger Straße 29, 09596 Freiberg, Germany

${ }^{\text {aj }}$ Faculty of Biology, Chemistry, Pharmacy, Freie Universität Berlin, Kaiserswerther Street 16-18, 14195 Berlin, Germany

${ }^{\mathrm{ak}}$ Federal Environment Agency (UBA), International Chemical Management, P.O. Box 1, 40606813 Dessau-Roßlau, Germany

al Shell Health, Shell Technology Centre, Thornton, P.O. Box 1, Chester CH13SH, United Kingdom

${ }^{a m}$ Environmental Safety, Syngenta Ltd., Jealott's Hill International Research Centre, Bracknell Berkshire RG42 6EY, United Kingdom

an Brixham Environmental Laboratory, AstraZeneca UK Ltd., Freshwater Quarry, Brixham, Devon TQS 8BA, United Kingdom

\section{A R T I C L E I N F O}

Article history:

Received 17 July 2013

Available online 23 October 2013

Keywords:

Cell lines

3Rs

QSAR

Read-across

Exposure-based waiving

Fish embryo test

Acute toxicity

Chronic toxicity

Endocrine disruption

Bioconcentration

\begin{abstract}
A B S T R A C T
Tests with vertebrates are an integral part of environmental hazard identification and risk assessment of chemicals, plant protection products, pharmaceuticals, biocides, feed additives and effluents. These tests raise ethical and economic concerns and are considered as inappropriate for assessing all of the substances and effluents that require regulatory testing. Hence, there is a strong demand for replacement, reduction and refinement strategies and methods. However, until now alternative approaches have only rarely been used in regulatory settings. This review provides an overview on current regulations of chemicals and the requirements for animal tests in environmental hazard and risk assessment. It aims to highlight the potential areas for alternative approaches in environmental hazard identification and risk assessment. Perspectives and limitations of alternative approaches to animal tests using vertebrates in environmental toxicology, i.e. mainly fish and amphibians, are discussed. Free access to existing (proprietary) animal test data, availability of validated alternative methods and a practical implementation of conceptual approaches such as the Adverse Outcome Pathways and Integrated Testing Strategies were identified as major requirements towards the successful development and implementation of alternative approaches. Although this article focusses on European regulations, its considerations and conclusions are of global relevance.
\end{abstract}

(c) 2013 Elsevier Inc. All rights reserved.

\section{Introduction}

Animal tests are an integral part of environmental hazard identification and risk assessment of industrial chemicals, plant protection products, biocides, feed additives and pharmaceuticals. They are also used to monitor the quality of effluents and surface waters to improve the assessment of the status of European waters under the auspices of the Water Framework Directive (EU, 2000). Depending on intended use, diverse regulations are applied that require different types of animal tests. This has raised ethical concerns with regard to tests using vertebrates in environmental risk assessment (mainly fish, amphibians, and birds; occasionally, mammals are used, for example for testing of rodenticides and plant protection products, EU, 2013, 2012c). Ethical concerns - according to European regulation (EU, 2010a) - apply also to cephalopods, but these are not commonly used in environmental risk assessment. Even though many regulatory frameworks principally encourage the use of alternative approaches such as 
(Q) SAR ((Quantitative) Structure-Activity Relationships), readacross, or alternative experimental test methods, there is opportunity to expand on the range of models, and domain of applicability ${ }^{30}$ using new data, and both scientific and technological advancements in the field. The use of alternative experimental test methods has been limited to date. A main reason - as discussed in detail in this review - is not a lack of available methods, but a lack of consensus on their applicability domains and international validation and regulatory acceptance including appropriate OECD (Organisation for Economic Co-operation and Development) test guidelines. With regard to the daily use of alternatives to animal testing, the field of human health hazard and risk assessment of chemicals seems to be more advanced, since for certain areas such as skin corrosion and irritation animal tests have been fully replaced by alternative testing methods and have already been implemented in European legal frameworks such as REACH (Registration, Evaluation, Authorisation and Restriction of Chemicals) and the Cosmetics Regulation (EU, 2006, 2009b).

The purpose of this review paper is to highlight the potential areas for alternative approaches in environmental hazard and risk assessment, including present limitations, as well as perspectives for further developments and subsequent implementations.

\section{Legal framework}

In the European Union (EU), chemicals ${ }^{31}$ are assessed under different legislative instruments (by substance type) with respect to their risks to humans and the environment (Table 1). Most industrial chemicals are regulated by the European Union regulation on chemicals and their safe use (EU, 2006) commonly known as REACH. Specific regulations exist for plant protection products (EU, 2009a, 2013), biocidal products (EU, 1998, 2012c), medicinal products for human and veterinary use (EMA/CHMP, 2006; EMA/CVMP, 2008) and feed additives (EU, 2003, 2008a). The environmental concerns raised by substances used in cosmetic products are considered through REACH (EU, 2009b).

The testing schemes and guidelines used in these different European regulations are strongly driven by international activities, mainly by the OECD, aiming at the harmonisation of testing and regulations (Koëter, 2003). The OECD provides harmonised test guidelines as a basis for the mutual acceptance of data principle, avoiding duplicative testing and costs by international sharing the burden of hazard assessment. Furthermore, the WHO, through the Global Harmonisation System (UN, 2011), has impacted on European regulation and animal testing via the CLP Directive (directive on classification, labeling and packaging of substances and mixtures; EU, 2009c), which is closely interlinked with REACH and the regulation of plant protection and biocidal products. In all the different regulations, the recommended testing procedures refer to OECD testing guidelines (Table 1).

To bring a new chemical substance/product to market requires in most cases that both the active compound and the final commercial product are shown to be safe for the environment. Therefore, an Environmental Risk Assessment (ERA) is included in the information dossier submitted to the relevant regulatory body. The specific regulations for the various types of substances

\footnotetext{
30 The applicability domain is the physico-chemical, structural or biological space, for which alternative testing approaches are applicable to make predictions. Even in case of limitations of alternative approaches, they may be still applied if this domain is clearly defined. Consequently, for compounds outside the applicability domain, hazard and risk assessment has to be based on established in vivo experimental or other alternative approaches.

31 The term "chemical" as used in this article refers to a chemical compound in general and - unless otherwise indicated - regardless of the potential application in industry, household, agriculture or medicine.
}

(industrial chemicals, pesticides, biocides, feed additives, pharmaceuticals) require the same type of animal testing, and refer to the same OECD testing guidelines (see Table 1). What distinguishes the different regulations are the thresholds and constraints as to when a specific test is required. Furthermore, the different regulations also address the distribution of a chemical into different environmental compartments, such as soil or surface water, and the resulting different exposure routes. Hence, testing of some classes of vertebrates, such as birds, is only required in some regulations (e.g. for plant protection products) and with relevance to the expected fate and exposure of the compound (Table 1).

Testing on fish is required to provide data on short-term and long-term aquatic toxicity. Additional studies may be triggered to assess bioaccumulation in fish (dependent on hydrophobicity, ${ }^{32}$ persistence and toxicity) and for identifying endocrine-disrupting chemicals (formal regulatory definitions for these compounds and triggers for testing are yet to be defined). A general strategy to integrate acute toxicity, chronic toxicity, bioaccumulation and endocrine disruption endpoints for fish was developed by OECD under the Fish Toxicity Testing Framework Program (OECD, 2012b). This OECD initiative includes scope for where alternative assays are or could be implemented. For the terrestrial environment, short- and long-term testing or testing of reproductive toxicity to birds is required for plant protection products, when a potential exposure is expected. Avian testing is required under REACH at high tonnage levels (>1000 t/a). However, given the large mammalian dataset available at this tonnage level, waiving of tests is often permitted and mammalian data are accepted as surrogates for non-mammalian tests. Under certain circumstances, testing of mammals may be considered in environmental risk assessment of plant protection and biocidal products, in order to assess the potential risk of so-called secondary poisoning, i.e. by accumulation via the food chain and from dietary exposure to contaminated food (EU, 2013, 2012c). However, usually the appropriate data would be already available from studies that had to be conducted for human hazard assessment. In the aquatic environment, uptake from food is not considered relevant for compounds with a $\log K_{\text {ow }}$ (octanol-water partition coefficient) $<4$ (Gobas et al., 2009).

There are also specific requirements for chemicals used offshore by OSPAR (Oslo and Paris convention, http://www.ospar.org/), a legislative instrument by which fifteen Governments of the western coasts and catchments of Europe, together with the EU, cooperate to protect the marine environment of the North-East Atlantic. OSPAR has established a Harmonised Offshore Chemical Notifications Format (HOCNF) which, under certain circumstances (Table 1 ), requires provision of acute fish toxicity and fish bioconcentration data (OSPAR, 2012).

Not only individual chemicals and their products, under some situations, are required to be tested for potential risk to the environment. Industrial effluents in the EU Member States are also subject to control for potential toxic effects to organisms in the environment, including water, sediment, soil and air. As stated in the Directive on Industrial Emissions Integrated Pollution Prevention and Control (IED) (EU, 2010b), industrial activities require an environmental permit, including a description of "the nature and quantities of foreseeable emissions from the

\footnotetext{
32 Hydrophobicity and lipophilicity are often understood as synonyms, particularly in the context of bioaccumulation. Considering the fact that for organic compounds their affinity to water varies by orders of magnitude more than their affinity to lipid or associated surrogates such as octanol, it is typically the former that drives the passive partitioning of xenobiotics from water into lipid. Accordingly, we prefer the term hydrophobicity, and interpret the octanol/water partition coefficient $K_{\text {ow }}$ as measure of hydrophobicity rather than of lipophilicity.
} 
Table 1

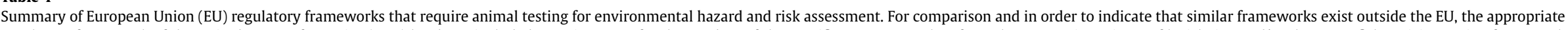

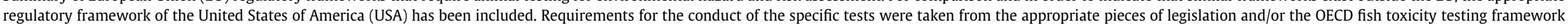
(OECD, 2012b). Legislations were abbreviated (see legend).

Test type/OECD guideline (or US EPA if appropriate) Regulatory framework

Number of animals

[typical design] needed

or testing of one

compound/sample

Europe

USA

Acute toxicity

OECD 203 and OCSPP 850.1075: Fish acute toxicity REACH. Required for compounds produced or imported $>10$ tonnes/year

test (US EPA, 1996a; OECD, 1992; US EPA, 2002) (conditional waiving is possible).

PPP. Mandatory for rainbow trout (threshold approach)

BioP. Mandatory for one freshwater species (and marine species if

relevant)(threshold approach).

VMP. Mandatory for Tier A.

FA.Required if PEC in surface water $\geqslant 0.1 \mu \mathrm{g} / \mathrm{L}$ or in sediments $\geqslant 10 \mu \mathrm{g} / \mathrm{kg}$.

HOCNF. Mandatory if not tested already under REACH. A limit test can be

used instead of a full acute fish toxicity test.

Effluent testing Sweden (Naturvårdsverket, 2010) (OSPAR, 2000) Denmark, Effluent testing Clean Water Act (US Congress 33 U.S.C. 1251)

France, Ireland, Norway (OSPAR, 2000)

Generally, a detailed guidance when acute fish toxicity should be assessed for Specific requirements for effluent testing vary on a state and regional effluents is missing. Acute fish tests are often required if "available data and basis and are usually defined within discharge permits. experience is insufficient"(OSPAR, 2000)

OECD 223 Avian acute oral toxicity test

PPP. Mandatory except where the active substance is intended solely to be

included in preparations for exclusive use in enclosed spaces (e.g. in glasshouse or in food storage practice)

TSCA FIFRA, mandatory (in multiple species including a passerine) 4

FIFRA: Cold and warm water freshwater species and 1 saltwater species

FFDCA: Tier 2 testing of drugs and biologicals for refinement of

assessment factors (US FDA, 1998)

(n)


Table 1 (continued)

\begin{tabular}{|c|c|c|c|}
\hline \multirow[t]{2}{*}{ Test type/OECD guideline (or US EPA if appropriate) } & \multicolumn{2}{|l|}{ Regulatory framework } & \multirow{2}{*}{$\begin{array}{l}\text { Number of animals } \\
\text { [typical design] needed } \\
\text { for testing of one } \\
\text { compound/sample }\end{array}$} \\
\hline & Europe & USA & \\
\hline OECD 215 Fish, Juvenile Growth test & $\begin{array}{l}\text { REACH. Can be performed instead of the Fish Early Life-Stage Test or Fish, Short- } \\
\text { term Toxicity Test on Embryo and Sac-Fry Stages. } \\
\text { PPP. Only required if Fish Early Life Stage Test or Fish Full Life Cycle Test are not } \\
\text { appropriate. } \\
\text { BioP. Required for PNEC refinement (if } \log K_{o w}<5 \text { ). }\end{array}$ & n.r. & n.a. \\
\hline $\begin{array}{l}\text { OECD 212: Fish, Short-term Toxicity Test on } \\
\text { Embryo and Sac-Fry Stages }\end{array}$ & $\begin{array}{l}\text { REACH. Can be performed instead of the Fish Early Life-Stage Test orFish Juvenile } \\
\text { Growth Test } \\
\text { Biocides: see REACH }\end{array}$ & n.r. & n.a. \\
\hline $\begin{array}{l}\text { Fish full life cycle test (not yet internationally } \\
\text { standardised, Crane et al., 2010; US EPA, 1998) }\end{array}$ & $\begin{array}{l}\text { PPP: Conditionally required in cases where the bioconcentration factor is } \\
\text { greater than } 1000 \text { and the elimination of the active substance during a } \\
\text { depuration phase of } 14 \text { days is lower than } 95 \% \text {, or the substance is stable in } \\
\text { water or sediment (DT90 > } 100 \text { days) (CTGB, 2013). }\end{array}$ & $\begin{array}{l}\text { FIFRA: conditionally required if estimated environmental } \\
\text { concentration } \geqslant 0.1 \times \text { FELS NOEC or studies of other organisms } \\
\text { indicate the reproductive physiology of fish may be affected (US } \\
E P A, 1996 b) \text {. }\end{array}$ & n.a. \\
\hline $\begin{array}{l}\text { Avian reproduction test (OECD TG 206, US-EPA } \\
\text { OCSPP 850.2300)) (US EPA, 2012; OECD, 1984) }\end{array}$ & $\begin{array}{l}\text { REACH. Conditionally required for chemicals produced or imported } \\
>1000 \text { tonnes/year. Any need for testing should be carefully considered taking } \\
\text { into account the large mammalian dataset that is usually available at this } \\
\text { tonnage level } \\
\text { PPP. Always mandatory for two species }\end{array}$ & TSCA, FIFRA, FFDCA Mandatory for two species & 96 \\
\hline \multicolumn{4}{|l|}{ Bioconcentration } \\
\hline $\begin{array}{l}\text { OECD } 305 \text { and OCSPP } 850.1730 \text {. Bioconcentration: } \\
\text { Flow-through fish test }\end{array}$ & $\begin{array}{l}\text { REACH. Required for chemicals produced or imported in over } 100 \text { Ton/year and } \\
\log K_{o w} \geqslant 3 \\
\text { PPP. Required for products with } \log K_{o w}>3 \text { and considered stable. } \\
\text { BioP. Required for anti-foulings, detergents and if } \log K_{o w} \geqslant 3 \text {. } \\
\text { HMP. Required if } \log K_{o w} \text { is } \geqslant 4.5 \text { and in Tier } B \text { if } \log K_{o w} \geqslant 3 \text {. } \\
\text { VMP. Required in Phase II Tier } B \text { if } \log K_{o w} \text { is } \geqslant 4 \text {. } \\
\text { FA. Optional for phase IIB } \\
\text { HOCNF. Mandatory if } \log K_{o w}>3 \text {, but bivalve test can be conducted } \\
\text { alternatively. }\end{array}$ & $\begin{array}{l}\text { TSCA. Conditional requirement } \\
\text { FIFRA. Conditional requirement }\end{array}$ & 108 \\
\hline \multicolumn{4}{|l|}{ Endocrine disruption } \\
\hline $\begin{array}{l}\text { OECD } 229 \text { and OCSPP 890.1350: Fish short term } \\
\text { reproduction assay }\end{array}$ & $\begin{array}{l}\text { REACH. Required in case of concern for endocrine disruption. (OECD, 2012b) } \\
\text { PPP. based on concern from mammalian and other data } \\
\text { BioP Required in case of concern for endocrine disruption. (OECD, 2012b) } \\
\text { HMP. Conditional requirement. } \\
\text { VMP. Conditional requirement }\end{array}$ & $\begin{array}{l}\text { TSCA, FIFRA, FFDCA: via endocrine disruptor screening program (US } \\
\text { EPA, 2011). EDSP tier } 1 \text { (US EPA, 2011) }\end{array}$ & $\begin{array}{l}80-96 \text { (European } \\
\text { regulations) (US n.a.) }\end{array}$ \\
\hline OECD 230 Fish screening assay & $\begin{array}{l}\text { REACH. Required in case of concern for endocrine disruption. } \\
\text { PPP. Required in case of concern for endocrine disruption. } \\
\text { BioP. Required in case of concern for endocrine disruption. } \\
\text { HMP. Conditional requirement. } \\
\text { VMP. Conditional requirement }\end{array}$ & n.r. & $80-96$ \\
\hline OECD 234 Fish sexual development test & REACH. Conditionally required in case of concern for endocrine disruption. & n.r. & $\begin{array}{l}840 \text { (definitive) } 480 \\
\text { (screening mode) }\end{array}$ \\
\hline
\end{tabular}




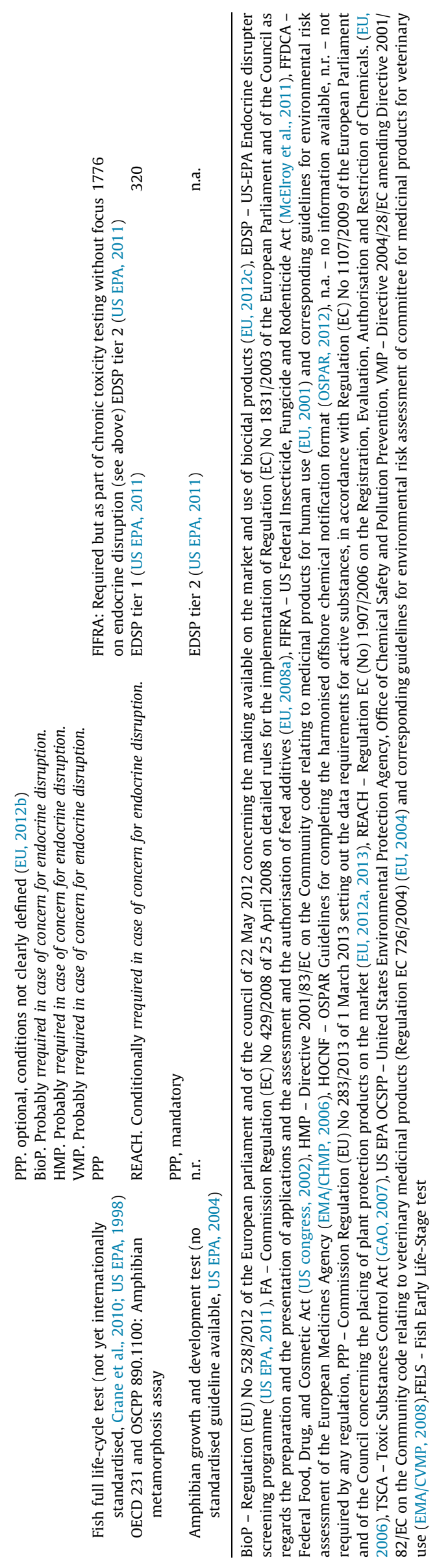

installation into each medium as well as identification of significant effects of the emissions on the environment" (IED Directive). The IED directive is closely linked to the Water Framework Directive (EU, 2000) that requires Member States to define reference conditions for the good biological and chemical status of receiving waters. Each Member State, however, has its own regulations and environmental quality standards, including the need to present ecotoxicological and environmental fate data. Some countries (Denmark, Sweden, Ireland, Norway, France) require fish toxicity testing to assess the effects of effluent discharge (Table 1; COHIBA, 2010; Embry et al., 2010; OSPAR, 2000). Fish testing for effluents was also required in the UK, but has been derogated due to animal welfare concerns (UK Environment Agency, 2006). According to the UK Environment Agency guidance document, algae and invertebrates are generally considered more sensitive than fish and sufficient to estimate effluent toxicity (UK Environment Agency, 2006). Fish tests are only required if there is a defined fishery at risk from acute effluent toxicity in the immediate vicinity of the discharge point. Germany has replaced previous acute fish toxicity testing for effluents by a standardized $48 \mathrm{~h}$ waste water test with zebrafish (Danio rerio) embryos (ISO 15088, 2007). However, in the USA and in Canada use of fish tests plays a more central role in effluent testing as underlined by the high number of organisms used (see Section 3).

\section{Number of animals used and status of acceptance of alternative approaches}

\subsection{Statistics on animal numbers}

On a tri-annual basis, the EU reports the number of animals used for experimental and other scientific purposes in its Member States. For the latest report available (EU, 2010c), summarising the numbers for the year 2008 of 27 Member States, about 12 million animals (vertebrates) were recorded. From this total, 1.9 million were fish, amphibians or birds, which comprise those vertebrates generally used in environmental hazard and risk assessment. About 250,000 fish and birds were used for toxicological and other safety evaluations with 140,000 animals tested for regulatory requirements (Table 2). The actual number of vertebrates used for environmental risk assessment might be higher, since animal testing in other areas, such as basic research, product development etc. may also relate to toxicological investigations. Furthermore, it is difficult to precisely calculate the number of animals used in the context of various regulations for environmental risk assessment, since the EU does not disclose fish, amphibians and birds used with respect to specific endpoints and regulations. Acute toxicity testing is mandatory in most regulations while chronic toxicity testing and BCF estimation is conditionally triggered by physico-chemical properties, exposure routes and/or tonnage levels (Table 1). However, for the implementation of REACH due to the higher number of animals needed per compound, chronic fish toxicity testing has been estimated to contribute to the majority of vertebrates needed for environmental hazard assessment in Europe (van der Jagt et al., 2004).

Finally, the fact that between 3 and 6 million fish per year are currently being used for whole effluent testing in the United States $^{33}$ and about 100,000 fish for regulatory testing of products for the protection of humans, animals, or the environment in Canada (CCAC, 2012) emphasises the pronounced need for alternative methods on a global scale.

\footnotetext{
33 The estimation is based on summarising information on types of tests done, their frequency, number of reports for effluent studies for US states where this information is available and an extrapolation to capture the entire US. Courtesy of S. Belanger.
} 
Table 2

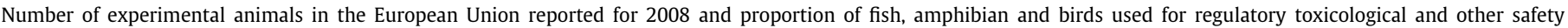

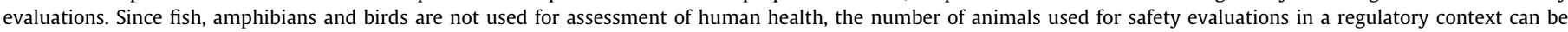
associated to environmental risk assessment. Data were obtained from the European Union report on statistics of animal use for 2008 (EU, $2010 \mathrm{c}$ ).

\begin{tabular}{|c|c|c|c|}
\hline \multicolumn{4}{|l|}{ Total number of vertebrates: $12,001,022$} \\
\hline Thereof used... & ...in any type of experiment (total) & ... in toxicity and safety analysis & ...for regulatory requirements \\
\hline - Birds & 764,111 & 53,128 & 50,603 \\
\hline - Amphibians & 61,789 & 291 & 179 \\
\hline - Fish & 1087,155 & 194,226 & 90,583 \\
\hline Total number of birds, amphibians and fish & $1,913,055$ & 247,645 & 141,365 \\
\hline
\end{tabular}

Occasionally, mammals are also used for environmental risk assessment, for assessment of hazards from diets and drinking water, and for secondary poisoning (see Section 2.). However, the EU statistics do not disclose the number of mammals that have been used specifically for environmental hazard assessment. Furthermore, mammals are only used in higher tier assessment when there is specific concern for environmental risk. It is common to use data from e.g. studies, which have already been performed for human hazard assessment. Therefore, the actual number of mammals specifically used for environmental hazard and risk assessment is low compared to fish and birds.

\subsection{Status of acceptance of alternative approaches focussing on REACH}

The REACH regulation states that "every effort must be made so that testing chemicals on animals is a last resort - when there is no other scientifically reliable way of showing the impact on humans or the environment" (EU, 2006). Nonetheless some estimations indicated that REACH may lead to a dramatic increase in the number of experimental animals used for risk assessment (Hartung and Rovida, 2009). The recent report of ECHA (see Box 1 on REACH regulation statistics for details with respect to animal tests in environmental risk assessment), however, indicates that alternative approaches are frequently referenced in the registration process of phase-in substances ${ }^{34}$ (ECHA, 2011;Spielmann et al., 2011). At least in the initial registration phase, the applicants (registrants) made extensive use of data sharing, which is one of the key mechanisms anticipated to avoid unnecessary animal testing. Furthermore, registrants made use of existing studies or non-test methods to predict properties of substances instead of experimental testing. The following non-testing approaches were cited: (1) use of information on similar substance (grouping and read-across); (2) information combined from various sources (weight-of-evidence); (3) studies using cells, tissues or organs (in vitro); (4) computer modelling ((Q) SAR, structural alerts etc.).

These data already indicate that there is a clear preference for alternative or non-testing approaches (see Box 1 on REACH regulation statistics). However, at present no data are available to dimension the extent to which ECHA has required additional animal testing for situations that registration dossiers have made use of hazard assessment based on alternative methods (ECHA, 2011). Furthermore, in some cases, particularly for acute fish toxicity testing, mainly data from animal studies (75\%) were submitted for the registrations. This may be due to the fact that such experimental data were already available for high tonnage substances. Whether these were derived from existing or new studies conducted for the

\footnotetext{
34 Existing compounds (EINECS repository, esis.jrc.ec.europa.eu.), compounds produced or imported in the EU but not placed on the market within 15 years before the entry into force of REACH, as well as compounds initially classified as polymers but that do not meet the definition of polymers as set out in REACH are summarised as "phase-in compounds".
}

purpose of REACH is unclear. It might be possible to avoid or reduce testing for future registrations by encouraging registrants to use alternative approaches in the initial phase of dossier formation. Due to a lack of experience by industry and regulators, it is, however, difficult to quickly arrive at an agreement on the ultimate acceptance of results by scientists, industry and regulators. This applies particularly for alternative experimental test systems, the development of which may take many years to complete, while new read-across and weight-of evidence cases and even some (Q) SARs can be developed within the timeframes imposed by legislation. The 2013 and 2018 REACH registration deadlines for lower tonnage substances will provide further insight into the use of alternative approaches.

Besides existing guidance (echa.europa.eu/web/guest/practical-guides) on how to report read-across, weight-of evidence and (Q) SAR, documents from a recent ECHA/Cefic-LRI workshop on read-across approaches inform about an envisaged readacross assessment framework as a possible instrument for streamlining information and documentation needs. The goal is to overcome the current problems associated with the fact that so far, it appears to be unclear when a given read-across approach is considered sufficient for regulatory acceptance, "and how the remaining uncertainty should be dealt with" (ECHA, 2012). ECHA is expecting that outcomes of compliance checks will allow a better understanding of the reliability of animal and non-animal test methods used by registrants and hence improve guidance on when alternative approaches are acceptable (ECHA, 2011).

While the case-by-case registration process considers the use of alternative or non-testing approaches, there are as of yet only a few validated schemes for the use of alternative approaches to predict effects for environmental risk assessment. The lack of validated methods available as OECD test guidelines or guidance documents (with the exception of the OECD guidance document 126 on the Threshold Approach for Acute Fish Toxicity and the recently approved TG 236 for the Fish Embryo Acute Toxicity Test; OECD, 2010, 2013) is probably one of the main reasons. An important nuance of the REACH guidance, however, is that an alternative does not need to be validated in the classic sense, including e.g. a properly designed ring test, but only needs to be "scientifically justified and supported", leaving open the possibility that methods not yet fully validated in the formal sense can be used (ECHA, 2008a). Explicitly this is stated in REACH, which requires (Q) SAR-models to be valid, not necessarily validated. Again, in practice, there is a lack of confidence within industry and regulators about this issue. As a result, to avoid uncertainties regarding the acceptability of their dossiers, industry has been reluctant to use alternatives. This may change in the 2013 and 2018 registrations, but to achieve the increased use of alternative approaches by the registrants, the availability of validated approaches (e.g. similar to the skin irritation/corrosion or eye irritation in vitro tests used for human risk assessment) is a requirement. 


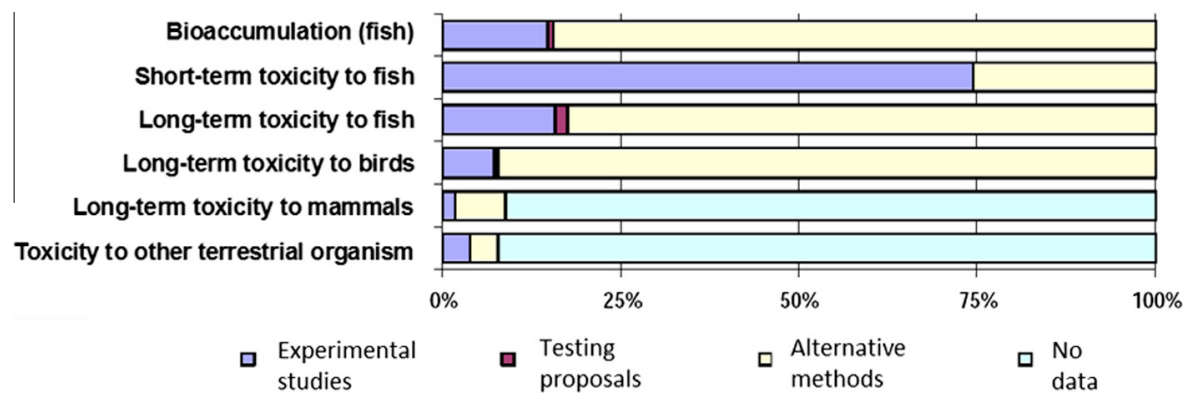

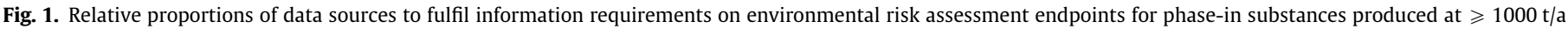

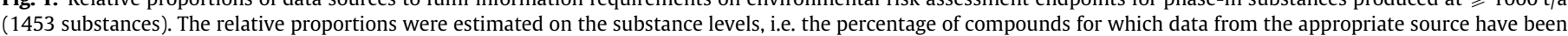
used. Reproduced from (ECHA, 2011) Source: European Chemicals Agency, http://echa.europa.eu/ (ECHA, 2011).

\section{REACH regulation statistics}

In June 2011, the European Chemicals Agency (ECHA) has released the first report on the use of alternatives to testing on animals for the REACH regulation (ECHA, 2011). ECHA analysed the registration dossiers for high tonnage substances (>1000 t/a) submitted between 1 June 2008 and 28 February 2011 and also included information of on-going $\mathrm{REACH}$ dossier evaluations. Data from $1504 \mathrm{REACH}$ dossiers covering phase-in substances were analysed for the percentage of registered substance, for which the registrants used alternative approaches. For vertebrate testing in relation to environmental risk assessment, the endpoints covered included bioaccumulation (fish), short- and long-term toxicity to fish as well as long-term toxicity to birds. With the exception of acute fish toxicity testing, alternative methods (testing and non-testing approaches; Fig. 1) provided the ecotoxicological information for more than $75 \%$ of the registered substances.

\section{Alternative approaches}

The 3R principles - replacement, reduction and refinement of animal tests (Russell and Burch, 1959) - can be met by various testing and non-testing approaches as described in more detail below. Such approaches address the design and statistics of animal tests or the replacement by alternative experimental and non-testing methods. Non-testing approaches make use of scenarios for exposure-based waiving, read-across, grouping and QSAR. Decision trees in non-testing approaches provide a framework to obtain the appropriate biological hazard information without animal testing and require animal test-based methods only as a last resort.

In this context, a major step forward has been the introduction of integrated testing strategies (ITS) as an operational means to accomplish the 3Rs at least partly and on a short-term basis (e.g. Hartung et al., 2013b;Grindon et al., 2006). The ITS approach for a certain endpoint takes into account results from several alternative methods, and exploits their combined information content. To this end, 3R-oriented methods - potentially relevant as ITS components - include alternative experimental methods (chemoassays, ${ }^{35}$ in vitro/embryo assays) modifications of existing animal testing schemes (Threshold Approach, Sequential testing, see Section 5.1) and non-test methods (read-across, structural alerts, (Q) SARs, exposure-based waiving, see Section 4.2). Appropriate ITS methods and

\footnotetext{
${ }^{35}$ Chemoassays measure the reacivity of a chemical to cellular molecules, such as glutathion or DNA. Model substrates may be used as surrogates for native cellular macromolecules.
}

guidance have been developed for both human and environmental hazard assessment (OSIRIS, 2011; Buist et al., 2013; Rorije et al., 2013; Tluczkiewicz et al., 2013; Grindon et al., 2006; ECETOC, 2007; ECHA, 2008b).

\subsection{Revision of test designs and risk assessment schemes}

Even without available alternative methods, there would be scope for a reduction of animal tests via modification of risk assessment schemes or experimental test designs. For instance, whether a benchmark dose/concentration or NOEC (No Observed Effect Concentration)/LOEC (Lowest Observed Effect Concentration) approach is preferred over a threshold (see Section 5.1) or categorisation approach in risk assessment can have a significant impact on the number of test animals. Many regulations require the classification of toxicity according to the United Nations Global Harmonisation System (GHS; UN, 2011). In Europe, this categorisation is required by the CLP regulation (EU, 2009c), which is closely interlinked to substance-type regulations on industrial chemicals, biocides and plant protection products. Principally, the CLP regulation could rely on limit tests, i.e. tests at predefined concentration (s) which are already routinely applied in human risk assessment for acute toxicity and require a reduced number of animals (Seidle et al., 2010). For environmental risk assessment, however, recent European guidance documents suggest provision of benchmark concentrations or NOEC/LOEC values (EU, 2008b). The limit test is already applied for acute fish toxicity at high exposure concentration. I.e. an $\mathrm{LC}_{50}>100 \mathrm{mg}$ is considered as not toxic and no classification or determination of benchmark concentrations, respectively, is required above this level (OECD, 1992). However, particularly biologically active compounds as often found among PPPs and biocides fall short of this limit.

A categorisation approach would not need full concentrationresponse data. I.e. it would principally require the testing of a limited number of concentrations offering the potential to reduce the number of test animals. However, the regression-based benchmark approach is often preferred and considered also advantageous over the determination of NOEC/LOEC (Sand et al., 2006). Regressionbased modelling of effect concentrations is less affected by sample size and data variability and more adequately describes the concentration-response relationship of a compound (Jager, 2012; Landis and Chapman, 2011). It is therefore not surprising that the development of alternative tests commonly deploys a regressionbased approach. This regression-based approach has also been approved by the OECD Working Group of National Co-ordinators in 2013 for a revised guideline of the FELS (Fish Early Life-Stage) test (OECD 210). Motivation for this change was driven by an analysis of OECD 210 studies by Oris et al. (2012) demonstrating that a 
large change of statistical power of the assay could be realized if all studies used a minimum of 4 replicates per treatment (not the minimum 2 as in the older guideline). Hence, the revision of the FELS has led to an increase in the required number of animals (from 60 to 80 fish per treatment as a minimum). However, a regression/benchmark approach may not per se require an increase in animal test numbers as this may be compensated by a reduced number of animals per group compared to a group-wise statistics. Nevertheless, even in case of an increase in animal test numbers, the higher statistical power may facilitate more reliable correlation with alternative methods. While we aim to reduce animal use in the long term, it is also equally important to avoid ineffective use of the animals in tests already used for environmental decisionmaking, since these animals may simply be wasted if poor or unsupportable conclusions are derived.

The number of test animals could also be reduced significantly by application of the 'Threshold of Toxicological Concern' concept. This concept was initially developed as a means to predict safe levels of food additives for human consumption (U.S. FDA, 1993) and has since been expanded to address a wide variety of human health endpoints including carcinogenicity, teratogenicity, and reproductive toxicity (Kroes et al., 2005; Kroes et al., 2004). The TTC has been applied in human health risk assessment by various regulatory bodies in the US and Europe (for review see Hennes, 2012). The concept aims at establishing a threshold level of exposure of no concern for chemicals with little or no data based on the comparison of the distribution of effect concentrations of chemicals for which there is data. Central to this paradigm is the waiving of tests in cases that exposure does not exceeds the threshold. Compounds of certain structural characteristics known to exhibit low effect concentrations may be exempted from the application of the 'Threshold of Toxicological Concern' concept. The TTC approach relies on the availability of sufficiently large dataset for a particular chemical structure series or mode of action. For environmental endpoints, use of a TTC has been substantially less, however attempts have been made (de Wolf et al., 2005; Gross et al., 2010; Williams et al., 2011) providing the groundwork for future investigations.

A critical review of global data requirements may also be useful to identify potentially redundant requirements for testing and to ensure greater international harmonisation. For example, a recent survey of European crop protection companies indicates that chronic fish toxicity testing of formulated PPPs (plant protection products) - a potential requirement under EU legislation - is rarely, if ever scientifically justified, as chronic exposure to the formulation per se rarely occurs in the environment (Creton et al., 2010). For bird testing, there are a number of international variations in terms of preferences for the use of particular species or protocols, leading to a number of tests on the same endpoint being conducted for one substance. It has not yet been critically analysed whether this partial redundancy by testing in multiple species is needed and whether a harmonisation in protocols and species would lead to a loss of information and safety with respect to the prediction of potential environmental hazards. Identifying and eliminating unnecessary requirements (e.g. international variations for test species preferences) to conduct in vivo testing, and improved international harmonisation could make a major contribution to the reduction of animal use. However, implementing such changes requires a scientifically sound base and close collaboration of international regulators.

\subsection{Non-testing approaches}

Various non-testing approaches have been developed to replace the use of animals in toxicological testing and to fill data gaps.
These approaches include (Q) SARs, structural alerts, grouping and read-across, the use of weight of evidence and data waiving.

(Quantitative) structure-activity relationships (QSARs) relate molecular properties of a compound to a measure of a particular activity, for example acute toxicity. The development of (Q) SARs requires toxicological data (e.g. from databases or directly from experimental data sets) that form the basis for developing predictive models). Over the past three decades, numerous models have been developed to predict physico-chemical properties that in turn may serve to assess acute toxicity towards fish or birds, bioaccumulation and other endpoints (Schüürmann et al., 2007). The most commonly used QSARs for environmental effects predict narcosislevel (baseline, non-polar narcotic) toxicity. Several computerised tools assist with the application of QSARs to predict environmental toxicity and bioconcentration, including VEGA (http://www.vegaqsar.eu), Petrotox (http://www.concawe.be), Petrorisk (http:// www.concawe.be), CEFIC LRI Tool box (http://www.cefic-lri.org/ lri-toolbox), MultiCASE (http://www.multicase.com), TOPKAT (accelrys.com/mini/toxicology/predictive-functionality.html) ECOSAR (as part of EPISuite http://www.epa.gov/opptintr/exposure/ pubs/episuite.htm), ChemProp (ChemProp, 2012;Schüürmann et al., 1997), PBT Profiler (US EPA, 2005), Toxtree (http://sourceforge.net/projects/toxtree/) and many others (see http://www. antares-life.eu for a compilation of available QSAR and other in silico models). With the financial support by the EU, the OECD has developed the OECD QSAR Toolbox, which is currently available as Version 3.1. (www.qsartoolbox.org) together with appropriate guidance. By analysis of the chemical classes represented among the more than 100,000 EINECS (European Inventory of Existing Commercial chemical Substances) substances, it was estimated that existing (Q) SARs were covering already about $57 \%$ of the EINECS compounds highlighting the relevance in safety assessment (Zvinavashe et al., 2009). It must be noted that QSARs only allow for the prediction of the toxicity of a single compound whilst regulations, on e.g. pesticides and biocidal products, may request the assessment of formulations. In order to predict the effects of variable compositions and formulations, appropriate mixture toxicity concepts also have to be included. Concentration Addition has been shown to provide a reasonable approximation for mixtures and could be applied in combination with QSARs if there is no indication of - generally rarely observed - synergism or antagonism (Kortenkamp et al., 2009).

Structural alerts: Originally introduced for categorical endpoints from human toxicology such as mutagenicity and carcinogenicity, structural alerts may also be used for the predictive discrimination between narcosis-level and excess toxicity towards aquatic organisms (Von der Ohe et al., 2005). Their derivation may result from a statistical analysis of existing toxicity data with the aim to relate the occurrence of excess toxicity to certain structural features, and through targeted in chemico or in vitro investigations of compound classes known for their general potential to exert specific, e.g. reactive, modes of toxicological action (Böhme et al., 2010; Blaschke et al., 2011; Schramm et al., 2011). While the structural alert approach does not yield a quantitative estimate of the $\mathrm{LC}_{50}$ or $\mathrm{EC}_{50}$ value, it provides guidance about whether or not a narcosis-level QSAR is expected to be applicable, and thus appears particularly useful as an in silico tool in the ITS context. Given the high level of confidence of existing narcosis-level QSARs for different aquatic species, structural alert schemes - if applied within their application domains - may contribute significantly to decreasing animal testing, supporting the identification of cases where a narcosis-level QSAR prediction can be considered confident.

Grouping-based read-across: Another in silico methodology is to group "similar" chemicals and perform read-across, i.e. interpolate the activity quantitatively through a trend analysis from a refer- 
ence set of similar chemicals for which toxicological data are available. Grouping or category formation alone may also assist in selecting and developing appropriate QSARs or may be useful for identifying prevalent mechanisms of action (OECD, 2007b; ECHA, 2010c; Carmichael et al., 2011). In this context, chemical similarity is a key issue, and may concern physico-chemical properties governing bioavailability, structural features, modes or mechanisms of toxicological action, and routes of metabolic activation or detoxification. Accordingly, grouping may become a complicated exercise (Blackburn et al., 2011), and activities to incorporate schemes for the similarity assessment by expert systems are ongoing within the OECD. Software that will assist in the grouping of compounds and read-across prediction of compound properties includes the OECD EQSAR Toolbox (http://www.qsartoolbox.org), ToxTree (toxtree.sourceforge.net), AMBIT (ambit.sourceforge.net/ ), and the OSIRIS edition of ChemProp (ChemProp, 2012).

Analogue-based read-across: In case only one or few sufficiently similar compounds can be identified, the resultant reference set is too small for performing a local trend analysis. Nevertheless, the analogue data for the endpoint of interest still provide an expectation basis for the respective value of the target compound, and thus can be used at least for a qualitative interpolation. Recently, an algorithm employing so-called atom-centred fragments (ACFs) used as an efficient general-purpose measure of structural similarity has been developed. This algorithm allows one to exploit data from only few analogues for predicting quantitative endpoints such as the acute toxicity towards fish (Schüürmann et al., 2011). This methodology is now fully automated (ChemProp, 2012), and can also be used to complement respective QSAR predictions as a basis for more elaborated consensus modelling and weight-of-evidence (WoE) approaches.

Weight-of-evidence (WoE) is an approach that involves the assessment of the relative weight of different pieces of available information that have been retrieved and gathered in previous investigations (Balls et al., 2006). To this end, a value is assigned to each piece of information using either an objective method (formalised procedure) or by expert judgement. The weight is influenced by factors such as the data quality, consistency of results, nature and severity of effects, relevance, etc. To build a weight-

of-evidence case, it is recommended to use information from all possible sources, including published literature, read-across from chemical analogues/homologues, QSAR, existing in vivo and in vitro studies, epidemiological data etc. (ECHA, 2010a), which are in line with the above-outlined ITS approach. In case of consensus results from different (preferably alternative) methods for a given target compound and endpoint of interest, a question is how to convert the individual method-specific levels of confidence (or uncertainty) to joint confidence (or uncertainty) for a consensus outcome, and what would be a statistically sound way to deal with conflicting results. Here, Bayesian statistics offer a solution towards a quantitative weight of evidence as illustrated recently with an ITS approach for skin sensitization (Rorije et al., 2013) that could be extended to endpoints relevant for environmental hazard assessment.

Data waiving: The EU REACH legislation provides the possibility to adapt and waive the standard testing requirements for several endpoints on the basis of a number of rules that aim to avoid unnecessary testing (ECHA, 2010b). Adaptation means the use of non-standard methods (e.g. QSAR, grouping and read-across) for fulfilling the information requirements, while waiving means that the submission of the standard information for the particular endpoint is considered scientifically unnecessary, technically not possible, or not necessary based on low expected environmental exposure concentrations in a specific case (ECHA, 2011). For environmental hazard assessment in $\mathrm{REACH}$, waiving of testing has been proposed for none of the endpoint study records ${ }^{36}$ (ESRs) for bioaccumulation and in only a very low number of ESRs for acute fish toxicity (1.8\%) in the dossiers registered as of 28 February 2011. For long-term fish toxicity, waiving was proposed by about $34 \%$ of the ESRs. No information is available on the actual number of acceptance of waiving (ECHA, 2011).

A specific example of a non-testing approach is the application of acute-to-chronic ratios (acute-to-chronic ratios). The prediction of ACRs represents a possible approach to identify compounds likely to induce chronic toxicity (see Section 5.2 for details). They are implemented for example in the Petrotox chronic toxicity prediction tool (Redman et al., 2012).

A major breakthrough in non-testing approaches can be expected from the determination of the mechanism of action and its propagation to apical endpoints (e.g. through advancement of toxicogenomic methods, pathway analysis, and formation of Adverse Outcome Pathways (AOPs, see Section 6.1). Understanding the mechanisms is a pre-requisite for appropriate grouping of chemicals and QSAR development. Structural alerts could be linked to such mechanisms and allow classifying compounds with potential specific effects, such as receptor-mediated toxicity.

Application of in silico models require a clear definition of their application domain, which is often lacking (Worth et al., 2007; Netzeva et al., 2005; Hewitt and Ellison, 2010). An application domain may consist of several components such as physico-chemical space (bioavailability), structural space (sub-structural features), descriptor space (QSAR model parameters), MoA space (prevalent modes of action), and metabolic space (biotransformation profile) (Dimitrov et al., 2005). In the context of aquatic toxicity and bioaccumulation, consideration of basic physico-chemical properties such as molecular weight, hydrophobicity $\left(\log K_{o w}\right)$ and water solubility, augmented by structural characteristics such as through the ACF approach (Kühne et al., 2009), would represent minimal criteria to describe the applicability domain, keeping in mind that ACFs may partly capture information on modes of action and the disposition for metabolic activation and detoxification. However, detailed accounts of MoAs and of the metabolic profile are crucial in improving both the application domain assessment and the prediction capability of in silico models.

For QSAR models, a major drawback is also the current limitation of a mechanistically sound quantification of reactive and other specific MoA to aquatic toxicity. While there is progress regarding the electrophilic class of Michael acceptors (Schwöbel et al., 2010; Mulliner et al., 2011), the associated QSAR models are not applicable across different compound classes, making their application domain correspondingly small. Regarding reactive toxicity, a way forward appears to expand research into in chemico and in silico approaches for profiling and parameterizing chemical reactivity.

Key issues in the development and application of (Q) SARs are e.g. the integration of data from various sources, the validation of in silico models for toxic effects, integration of confidential data, transparency of models and the need to establish an open standard to promote interoperability and further development and application (Hardy et al., 2010). These issues have been addressed by the EU-funded project "OpenTox" (http://www.opentox.org) which developed an Open Source- and Open Standards-based predictive toxicology framework. Underlying these developments is the creation of a new open standard: the OpenTox Application Programming Interface. For example, OpenTox has been extended to support the infrastructure development of ToxBank supporting the integration of in vitro, toxicogenomics ${ }^{37}$ and in silico evidence

\footnotetext{
${ }^{36}$ Endpoint study records (ESRs) summarise all endpoints reported in the dossiers. For each endpoint, more than one ESR per dossier may have been submitted.

37 Toxicogenomics is defined here as profiling of changes in the transcriptome, proteome and metabolome.
} 
on the SEURAT-1 program (http://www.seurat-1.eu), which aims to develop replacement methods in repeated dose toxicity (Kohonen et al., 2013). Similarly the OpenTox approach could be applied to the sector of environmental hazard assessment.

The OECD has already developed guidelines for (Q) SAR model development to help increase their acceptability for regulatory purposes (Zvinavashe et al., 2008). These guidelines propose that (Q) SAR models should be associated with (i) a defined end point, (ii) an unambiguous algorithm, (iii) a defined domain of applicability, (iv) appropriate measures of goodness-of-fit, robustness, and predictivity, and (v) a mechanistic interpretation. Specifically, the following additional steps are needed to allow for a broader application and acceptance of non-testing approaches in the implementation of the 3Rs in environmental risk assessment: (1) better use of non-testing data such as mechanistic information and extrapolations from existing human risk assessment data; (2) development of improved QSAR-models for chronic toxicity; (3) better definition of cut-offs, e.g. for solubility and volatility to aid bioavailability modelling; (4) development of in silico models for non-fish species, i.e. birds, and amphibians; (5) development of expert decision systems by combining outcomes of different data sources (experimental vs. in silico vs. others), while focusing on mechanistic knowledge-based approaches.

\subsection{Experimental model systems}

There is a wide range of alternative test systems available, the majority of them based on use of organ- and tissue-based or cellular in vitro systems and embryonic life stages (more details are provided in Section 5). Technologies to quantify responses of these systems range from more traditional approaches, such as mortality or viability analysis to increasingly sophisticated technologies, such as reporter gene assays and toxicogenomics technologies, which allow a system-wide view on various molecular and biochemical levels (Schirmer et al., 2010). As such, alternative systems have great potential to support the identification and elucidation of modes/mechanisms of action, development of AOPs (Ankley et al., 2010), and to serve in tiered testing approaches (e.g. Volz et al., 2011; Murk et al., 2013). Moreover, many of these approaches are amenable to high-throughput screening, finding utility in both the private sector (for exclusion and prioritization testing), in regulatory testing and for field biomonitoring.

Ultimately, the alternative assays, be it alone or in combination, need to be predictive of an outcome and corresponding effect concentrations of relevance to regulators (e.g., reproduction, development, etc.). This should result in the development of models, which are sufficiently predictive, or include them as an element in an integrated testing strategy with enhanced predictive value (Grindon et al., 2006). To this end, AOPs need to be constructed and assays developed and validated (Hartung et al., 2004; Archer et al., 1997; Hartung et al., 2013a) to specifically allow those links. For mechanistic information, especially if related to highly conserved genes and proteins, lessons learned from toxicogenomics approaches in the human health area, e.g. the US EPA ToxCast program (Kavlock et al., 2007; Collins et al., 2008; Sun et al., 2012), should be evaluated for their potential for extrapolation to vertebrate models used in environmental risk assessment.

To make full use of alternative test systems, all information available should be used as part of a weight-of-evidence approach. A challenge here is to use information among different domains. In attempting to meet this challenge, it is important to incorporate knowledge from mammalian toxicology studies, since these may precede ecotoxicological hazard assessments and are often more advanced at the level of molecular, mechanistic research and in the application of innovative approaches such as toxicogenomics.

\section{Replacement/reduction perspectives of endpoints relevant in the regulatory framework}

There are a limited number of endpoints relevant for environmental hazard assessment and required by regulatory frameworks (acute toxicity, chronic toxicity, endocrine disruption, bioconcentration). Various approaches for replacement or reduction of animal tests addressing these endpoints have been suggested, including refinement of test designs, non-testing approaches and the use of alternative experimental test systems (see Section 4.). At present, acute fish toxicity appears to represent the endpoint where the predictive capacity of alternative approaches is most advanced and also validations have been successfully conducted. Hence, this endpoint might be considered as a hallmark to implement alternative approaches in the regulatory framework for environmental hazard and risk assessment. For acute bird toxicity, the most recent guideline, OECD TG 223, can already be regarded as a reduction and refinement compared to the older test guideline in that the number of experimental animals has been reduced. The relatively small number of animal tests conducted to assess acute avian toxicity in the EU (required only for plant protection products or high tonnage levels for REACH) may explain the weak activities to identify replacement approaches. Therefore the focus on alternative approaches to acute toxicity testing in this article will be on fish. However, globally acute studies on birds are conducted for every formulated plant protection product (PPP) registered in certain countries (e.g. Brazil; IBAMA, 1996).

In the following sections, the present status and perspectives of alternatives specific for a certain endpoint of regulatory relevance are described. It should be noted that many of these endpoints, irrespective of the regulatory scheme and substance type, share similar limitations and challenges for improvement. This applies, for instance, to the mechanistic understanding, consideration of toxicokinetics and test design, which is more comprehensively discussed in Section 6.

\subsection{Alternatives to acute fish toxicity testing}

The determination of acute toxicity of chemicals to fish according to the OECD test guideline (TG) 203 is an integral component in numerous national and international legislations (OECD, 1992). OECD TG 203 has been nominated for revision on occasion of the discussion of the OECD fish toxicity testing framework (OECD, 2012b). In fact, given the significant variability of acute fish toxicity data found in databases and the open literature (Hrovat et al., 2009), there appears to be a potential for improvement during revision of this TG. In terms of the $3 \mathrm{R}$ principles replacement, reduction and refinement, the Fish Embryo Acute Toxicity Test (FET, OECD TG 236) with the zebrafish and genuine in vitro methods, such as fish cell culture tests, are under discussion and partially already adopted. The latter is illustrated by the example of current practices in whole effluent testing in Germany, where a complete replacement of acute fish tests by the a $48 \mathrm{~h}$ FET has been achieved for waste water regulations (Federal Law Gazette, 2005). The FET shows an excellent correlation to re-evaluated acute fish toxicity data (Lammer et al., 2009a) and an update by Belanger et al. (2013) on the basis of a total of 220 chemicals covering a diverse group of chemicals has resulted in an almost perfect correlation. Included in this compilation are data by Knöbel et al. (2012) which show high correlation despite the explicit analysis of chemicals with different modes of action and physico-chemical 
properties. A few outliers, i.e. compounds which exhibit a significant lower sensitivity in fish embryos - were observed in this study and could be related to the metabolic capacity, high hydrophobicity $\left(\log K_{o w}>6\right)$ and/or mode of action demonstrating some potential restriction in the applicability domain.

Cell cultures also have good promise as alternatives to acute fish toxicity testing (Bols et al., 2005). A considerable number of studies compared in vitro cytotoxicity of chemicals to fish cell lines with the in vivo fish acute toxicity and confirmed the general usability of fish cell lines (reviewed by Schirmer, 2006). However, fish cell lines are not yet part of any regulation. A major stumbling block thus far was an apparent underestimation of in vivo toxicity by the fish cells by up to three orders of magnitude (Schirmer, 2006). Schirmer (2006) proposed several routes for advancing fish cell line-based toxicity assays to overcome the aforementioned hurdle: selecting cell lines derived from tissues reflective of the chemical's site and mode of action; increasing sensitivity of the cellular response by modification of the culture environment to more closely resemble the in vivo exposure; and by accounting for the chemical fraction available to the cells. By realizing these suggestions, Tanneberger et al. (2013) demonstrated a very good correlation between the effective concentrations seen in a rainbow trout (Oncorhynchus mykiss) gill cell line (RTgill-W1), and acute lethal concentrations in fish (likewise close to the line of unity as observed for FET $v s$. acute fish toxicity).

The systematic analysis of outliers in the correlation of cell lines or embryos with acute fish toxicity should be used to limit the applicability domain or develop measures for further improvement of predicting acute fish toxicity. Such a systematic analysis could identify specific mechanisms of action or physico-chemical properties for which acute toxicity in alternative test systems might be under- or over-estimated. Minimising the potential for false negatives would help improve the acceptability/validity of the alternative test systems.

Improved test designs such as in the Sequential Testing (Up/ Down Approach; Sunderam et al., 2004), the Threshold Approach (OECD guidance document 126; OECD, 2010; Creton et al., 2013a) or the Threshold (Step-Down) Approach (Jeram et al., 2005; Hutchinson et al., 2003) can significantly reduce the number of test animals. In Sequential Testing, only one fish is tested at a time starting with an estimate of the expected $\mathrm{LC}_{50}$ concentration. Subsequent tests are conducted with concentrations 1.3-fold above or below the previous concentrations, depending on the outcome of the previous test. Sequential testing is used already in bird acute testing (OECD TG 233) but has not been included in acute fish toxicity guideline and guidance. While the traditional test design (according to the OECD 203) requires at least 42 fish, Sequential Testing only needs 6-7 fish. However, a major limitation to Sequential Testing is the time it takes to derive an $\mathrm{LC}_{50}$ value, the multiplication of preparing and analysing test solutions, and potentially the increase in fish size (growth) during the sequential testing. Therefore, it may not be used too frequently. In the Threshold Approach the test design follows the requirements of the limit test as described in the OECD 203 guideline. A test with fish is carried out at a single concentration (threshold concentration) which corresponds to the lowest of the $\mathrm{EC}_{50}$ concentrations obtained with previous tests on algae and Daphnia. If fish mortality occurs at this concentration, a full OECD 203 would be required. If no mortality is observed, no further testing is required since fish are not the most sensitive test species. A reduction of test animal numbers by 32 $47 \%$ was estimated, depending on the database that was used for the retrospective analysis (Hoeger et al., 2006; Creton et al., 2013a). The basis for the Threshold Approach was the Threshold (Step-Down) Approach, which uses fewer fish per concentration and instead of a full OECD 203 test, 3.2-fold dilutions of the threshold concentrations are tested step-wise as long as mortality is ob- served. This method was also evaluated with various existing acute toxicity data sets, including agrochemicals, industrial chemicals, and pharmaceuticals. Theoretical applications of the Threshold (Step-Down) Approach would have result in a reduction of 54$88 \%$ of the number of animal that would have been needed according to the standard (OECD TG 203) acute fish toxicity test (Hoekzema et al., 2006; Hoeger et al., 2006; Jeram et al., 2005;Hutchinson et al., 2003). The different reduction levels in the Threshold (Step-Down) Approach depend on the data source, whether conduction of a limit test was assumed for the acute fish toxicity test according to OECD TG 203 or whether a group of control animals was considered as necessary. However, the different variations of the threshold approach may interfere with some risk assessment schemes (e.g. for PPPs), that use varying assessment factors for fish (100), Daphnia (100) and algae (10). Hence, in the case that algae represent the most sensitive species, a lower risk could be predicted with the threshold approach if compared to a standard fish acute toxicity test. Further, where higher tier refinements are used for aquatic invertebrates or algae (e.g. mesocosm studies) the fish toxicity endpoint may drive the risk assessment even though it is not the most sensitive species. Therefore, in these cases careful selection of the threshold is required to achieve animal reductions and meet the requirements of the environmental risk assessment. Both the Sequential Testing and the different Threshold Approaches may also be combined with alternative test systems such as fish cell lines or fish embryos (Rufli and Springer, 2011).

In silico methods such as QSARs, (computerised) read-across variants (Schüürmann et al., 2011) and structural alert schemes can also help to reduce testing for acute toxicity in fish. In the ITS context, chemoassays such as non-animal experimental methods allow the determination of the toxicity-relevant reactivity (Böhme et al., 2010). This can provide pertinent information about the potential of a given compound for exerting reactive toxicity as opposed to narcosis-level toxicity, the latter of which can be predicted reasonably well from respective QSARs. A further 3R opportunity is given by weight-of-evidence approaches or consensus modelling, evaluating the combined information content from several (non-test and experimental) ITS components in order to compensate for individual method drawbacks (see Section 4).

\subsection{Chronic toxicity}

Due to improvements in environmental regulations, it has been recognised that, with the exception of accidental spills, acute toxicity of contaminants is unlikely to occur, and continuous or repeated exposure to sublethal concentrations represents the typical environmental situation. Consequently, the estimation of chronic toxicity or long-term effects can be considered as one of the most relevant categories in environmental hazard and risk assessment resulting in requests for chronic toxicity testing in fish and birds (and in case of plant protection products also mammals) by various regulations (see Section 2, Table 1). Chronic toxicity testing involves prolonged exposure to the test substance over a significant portion of the organism's lifecycle and may even include exposure over multiple generations.

However, due to the high costs and workload of such tests it is common to conduct abbreviated tests, which may include highly sensitive stages, such as the FELS test (OECD TG 210). Consequently, the focus on alternatives to chronic fish toxicity testing is presently with the FELS test. However, there is an increase in the requirements for fish full lifecycle studies particularly following extensive screening programs to identify chemicals which have potential endocrine disrupting properties (e.g. the US-EPA's Endocrine Disrupter Screening Program, (US EPA, 2011), see also 5.3 for details). For chemicals where effects are observed in the screening studies there is a need to investigate further in a higher-tier fish 
full life-cycle study (Crane et al., 2010). Likewise, various EU directives (CTGB, 2013; EU, 2009a) and US legislation (http:// www.epa.gov/oppefed1/ecorisk_ders/toera_analysis_eco.htm, McElroy et al., 2011) require fish full life-cycle studies where certain criteria (toxicity, persistence and bioaccumulation) are met. In the US, pesticide requirements include fish full life-cycle tests in both freshwater and marine species depending on product and proposed uses.

The development of alternatives to animal testing for chronic toxicity has mainly been focussed on fish, probably due to fish representing the largest group of experimental vertebrates in environmental hazard assessment. Other species such as amphibians are currently used only in specific applications e.g. chronic toxicity related to endocrine (thyroid hormone) disruption - and, hence, development of alternative test systems have focussed mainly in this area (Scholz et al., 2013) (see Section 5.3). Activities to develop alternatives to avian chronic toxicity are rare. A few in vitro experimental studies have, however, addressed potential chronic effects such as immunotoxicity in lymphocytes and expression of specific mRNAs in avian hepatocytes, neural cells or cardiomyocytes (Ravindra et al., 2006; Jones and Kennedy, 2009; Vongphachan et al., 2011;Crump et al., 2011). Some of these endpoints may be useful to predict long-term effects, but these studies have neither been explicitly designed nor been validated for this purpose. QSAR models have not been reported for chronic toxicity in birds.

Two fundamentally different approaches have been proposed for the reduction of chronic fish toxicity tests in environmental risk assessment:

Acute to chronic ratios (ACRs): Prediction of ACRs, the quotient of the effect concentrations of acute toxicity and chronic toxicity, is anticipated to enhance the ability to identify compounds that are likely to cause chronic effects (Kenaga, 1982; Raimondo et al., 2007; Ahlers et al., 2006). In this approach the acute toxicity is typically derived from a regression-based modelling, while for chronic toxicity NOECs have been used. The principal assumption is that compounds characterised by a high ACR $(>10$ or $>30$ are used as thresholds) may exhibit specific physico-chemical characteristics, structural properties or modes of action and that these specifically acting toxic compounds could be identified by analysing their characteristics. Specific action would be needed to assess whether the concept is applicable for numerous classes of compounds.

An ACR of 10 was proposed and applied for the extrapolation from acute to chronic toxicity for mixtures, since this factor was found to represent the average ratio of the $\mathrm{LC}_{50}$ of acute to the NOEC for chronic toxicity (De Zwart, 2002; Van den Brink et al., 2006). For non-specific, narcotic compounds, for example hydrocarbons from petroleum, an empirical ACR prediction model based on the target lipid model has been developed (McGrath and Di Toro, 2009; Redman et al., 2012). The model is based on the critical target lipid body burdens, considers low bioavailability of highly hydrobphobic compounds $\left(\log K_{o w}>6\right)$ and utilises a database derived from acute and chronic effect concentrations of 55 organisms. It was hypothesised that specifically acting compounds would show a more pronounced time-dependence of toxicity than narcotics. Application of the 4-MoA and 7-MoA classification schemes of Verhaar et al. (1992) and Russom et al. (1997), respectively, demonstrated that narcosis-level toxicity in the acute exposure regime is often associated with low ACR values (Ahlers et al., 2006). A further interesting result is that the highest ACR values were found for compounds with $\log K_{o w}$ values around 4 to 5 suggesting that chronic toxicity is partially and particularly in case of limited metabolism associated with bioconcentration. However, for the application in a regulatory framework in order to predict chronic toxicity, a reliable approach for the ACR assessment of individual compounds including non-narcotics would be needed.
This is illustrated by the comparison of acute and chronic toxicity for a set of 32 new and existing industrial organic chemicals with data validated by governmental authorities (Ahlers et al., 2006). For these compounds, the median, 90th percentile and maximum ACR was $10.5,198.2$ and 4250, respectively. Assuming a factor of e.g. 100 as upper ACR level would not be protective at the $90 \%$ level of confidence. The substantial variation in observed ACRs is likely to reflect the fact that the prevalent MoA may vary with exposure time, and that the extent of this variation also depends on the MoA type.

Adverse Outcome Pathways (AOPs): Recent initiatives have proposed making larger use of information from alternative methods in a more mechanistically-assisted risk assessment approach (Volz et al., 2011). This approach, which is also referred to as the AOP concept (Ankley et al., 2010), aims to provide causal links between chemical exposure, the molecular initiating event, specific key events in the toxicity pathway and the adverse outcome at the individual or population level. Identifying the molecular initiating and/or key events characterising an AOP may allow prediction of chronic toxicity. The AOP approach may not be an absolutely new concept, but it is the first time that the principles have been formalised and that regulators became aware of its perspectives with regard to replacing animal tests (OECD, 2012e; Villeneuve and Garcia-Reyero, 2011).

A limitation of alternatives for chronic toxicity testing is the restricted ability to predict a variety of complex long-term effects in the whole organism from short-term testing. However, since most if not all types of toxicity can be explained by an initial molecular interaction, the identification and quantification of molecular interactions and their corresponding AOPs provide a key to develop alternative assays for the prediction of long-term effects. For instance, a comparison of the LOEC of FELS tests and gene expression data in fish embryos has indicated a concentration-dependent differential expression of marker genes below concentrations causing acute toxicity effects and close to LOECs in the FELS test (Weil et al., 2009; Voelker et al., 2007). Likewise, other studies have focused on the analysis of molecular endpoints in alternative test systems, i.e. fish embryos, primary and permanent fish cells. The major challenge to use this molecular information would be to link them mechanistically to AOPs in order to provide a causal and quantitative (with respect to effect concentrations) link to apical endpoints. A tiered, mechanism-based scheme focusing on molecular and cellular targets linked to AOPs in fish cells or embryos has been proposed to replace or prioritize testing with the fish early life-stage test (Volz et al., 2011). It is as yet not clear which type of sublethal, cellular endpoints or combinations thereof will provide a sufficient predictive power for chronic effects or mechanism associated with chronic toxicity, and further research is needed in this field. Toxicogenomic approaches are likely to support the development of AOPs provided that suitable markers for prediction of apical endpoints emerge.

The prediction of chronic effects in non-target organism by using human therapeutic data has been proposed as a way forward to avoid and reduce the number of animals in environmental risk assessment - particularly for pharmaceuticals given the availability of human data (Schreiber et al., 2011; Huggett et al., 2003; Scholz et al., 2010). Similarly, effect concentrations from mammalian species obtained for the human risk assessment of industrial chemicals, pesticides and biocides could be utilised. Invertebrate tests could also provide useful information, although species differences in sensitivity must be considered carefully. In order to deploy mammalian or invertebrate information, a retrospective analysis of existing data would allow a first estimate as to whether this approach can be applied in principle. However, such an evaluation has not been conducted so far. 


\subsection{Endocrine disruption}

Endocrine disrupting chemicals (EDCs) can, according to the WHO International Programme for Chemical Safety (IPCS), be defined as "... .exogenous substances that alter function(s) of the endocrine system and consequently cause adverse health effects in an intact organism, or its progeny, or (sub) populations" (UNEP, 2012). Concern over endocrine disruption by chemicals has led to recent legislative changes in Europe (ec.europa.eu/environment/ endocrine/index_en.htm) and North America aimed at the identification of potential endocrine mediated effects using screening tools and the prediction of adverse effects using long-term ecotoxicological tests (e.g., the US Endocrine Disruptor screening program, http://www.epa.gov/scipoly/oscpendo/index.htm). At the screening level, both mechanistic in vitro assays (e.g. receptor-binding assays, reporter gene assays for estrogenic, androgenic or thyroid hormone disrupting effects) and in vivo assays (e.g. fish and amphibian screens, Table 1) are being performed. Higher tier or confirmatory tests focus mainly on reproduction and development in order to predict population-relevant effects and, hence, represent the most animal-intensive tests used in environmental risk assessment (e.g. fish full life-cycle and avian two-generation tests). Alternative methods at the screening level are currently available for a limited number of endpoints. These concern receptor-binding affinity (including estrogen and androgen receptor binding affinity, estrogen receptor transactivation, cell proliferation in vitro assays) and interference with steroidogenesis. The intention, at least within Europe, is that alternative methods can be used in combination with all other relevant information such as pre-existing eco/toxicological data, QSARs and read-across to select subsequent in vivo assays (for example see Knacker et al., 2010; Bars et al., 2012; Bars et al., 2011). Putative endocrine effects need to be compared to systemic or other specific toxicity to estimate whether these are truly endocrine-mediated or reflect secondary responses (e.g. Munn and Goumenou, 2013; Wheeler et al., 2013). This is important with regard to the severe regulatory consequences of endocrine disruption of a chemical under certain parts of European legislation (e.g. removal from market or restrictions) and therefore, highlighting the importance to satisfy both components of the WHO/IPCS definition by establishing causality between adverse effects and an endocrine mode of action.

There is scope, however, within the currently available tools, to reduce the overall use of animals in the identification and assessment of endocrine disrupters in fish and amphibians. These include (i) making good use of the information available from tests with other vertebrates including mammals, (ii) the application of in vitro approaches and working to enhance the number and power of these methodologies, (iv) the use of invertebrate alternatives or vertebrate embryos, ( $v$ ) in silico approaches and (vi) refinement and improvement of the current in vivo tests.

\subsubsection{Use of mammalian data}

It is most likely that endocrine specific testing in ecotoxicological species will be triggered by concerns from the mammalian toxicology database in combination with relevant in vitro studies (where available). These in vitro assays, although of mammalian origin, address basic molecular mechanisms and, hence, can be considered as relevant to environmental species (e.g. Witters et al., 2010; Freyberger et al., 2010). The combination of a weight-of-evidence evaluation using peer-reviewed literature, read-across information from structurally similar substances and in vitro screening or in vivo mammalian data may provide sufficient information to waive screening or definitive tests (required by regulation) typically conducted for environmental risk assessment.

\subsubsection{Use of in vitroapproaches}

Hormone systems are very complex and include aspects such as central regulation via the hypothalamus-pituitary-gonad or -thyroid-axis and hormone production. However, there are systematic approaches to identify the biological relevance of known targets for endocrine disruption. For mammalians, several test guidelines (TGs) based on the use of cultured cells are now being developed at the OECD for the detection of endocrine activity. Currently available are OECD TG 455 transcriptional activation assay for the detection of estrogen agonists (OECD, 2009b) and OECD TG 456 steroidogenesis assay (OECD, 2009a). Also for thyroid hormone disrupting chemicals a battery of in vitro tests that can replace in vivo testing has been identified (Murk et al., 2013). This approach currently is being followed up by an OECD thyroid hormone scoping working group. For fish and amphibians, at present no guidelines for alternative assays are available. However, comparison of existing in vivo and in vitro data for fish and amphibians indicate a correlation and partially similar sensitivity, particularly for compounds of which the endocrine disrupting effects are mediated by receptor binding (Scholz et al., 2013). There are concerns that in vitro tests capture substances with endocrine activity, without discrimination of their potency (Weltje et al., 2013). As more data and greater experience is obtained with in vitro methodologies and as responses are calibrated with in vivo tests, appropriate 'cut-off' thresholds for positive in vitro responses could be established. For example, positive outcomes in receptor-binding assays are often identified only at unrealistically high exposure concentrations, which are already cytotoxic (Scholz et al., 2013). Therefore, low potency in relation to cytotoxicity at the in vitro level could be considered as a negative result and thus not be a priority for further need of confirmatory in vivo tests. Such an approach would need to be balanced with other limitations inherent to in vitro assays such as limited metabolic activation (Beresford et al., 2000).

\subsubsection{Use of invertebrates and embryos}

Invertebrate species: The endocrine system of several invertebrate species shares similarities with vertebrate species. An example are echinoderms such as sea urchins (Porte et al., 2006) that also undergo a thyroid hormone-dependent metamorphosis. Assays using echinoderms are able to identify thyroid hormone-disrupting compounds (Anselmo et al., 2011;Anselmo, 2012). It is, however, acknowledged that endocrine targets (e.g. estrogen receptors) are not universally conserved across taxa (Gunnarsson et al., 2008); thus, read-across between phylogenetically distant species may be challenging.

Fish and amphibian embryos: Embryos may also prove useful as alternatives for endocrine disruption testing. If the embryo test is designed to tackle receptor interaction, primary target genes for hormones can be investigated and particularly transgenic strains could be useful to screen hormonal effects. Transgenic strains responsive to estrogens (zebrafish cyp19a1b:GFP, e.g. Brion et al., 2012) or thyroid hormone interaction (zebrafish TSH:eGFP and tg:mCherry, Xenopus TH/bZIP:eGPF; Ji et al., 2012; Fini et al., 2012; Opitz et al., 2012) represent appropriate examples. For the Xenopus TH/bZip:eGFP construct, an OECD validation study has already been initiated (OECD, 2012d). Moreover, compounds interfering with thyroid hormone synthesis have been monitored in fish embryos by analysing T3 hormone levels using an immunochemical approach (Thienpont et al., 2011).

\subsubsection{Refinements to in vivo approaches}

Alternative test systems have only recently reached the point where they are applied widely in regulatory testing and screening schemes (e.g. the US-EPA's Endocrine Disrupter Screening Programme, http://www.epa.gov/endo). Consequently, there is at 
present insufficient data available to assess if there are opportunities to improve the $3 \mathrm{R}$ aspects of these methods. However, already the refinement of recent in vivo approaches offers the potential of significant reduction of test animals.

Species choice. Typically, the OECD test guidelines for endocrine disruption testing are developed for at least the three standard fish test species (fathead minnow, medaka and zebrafish). There are strong regional preferences and different biological advantages to determine the choice of the species such as availability of secondary sex characters (e.g. medaka and fathead minnow versus zebrafish), or body size making blood sampling easier (e.g. fathead minnow). This species choice can affect the number of animals required. For instance, a fish short-term reproduction assay according to the US EPA guideline OCSPP 890.1350) with fathead minnow would use about 152 fish, whereas a fish screening assay (OECD 230) test with zebrafish would only use 80 fish (US EPA, 2009; OECD, 2012b). The current practice of species and test choice should be analysed critically with respect to determine whether a particular species or test gives higher confidence for environmental protection. If there is no rationale for the use of a particular species, a reduction of the total number of animals used could be achieved by mutual acceptance of the results of a particular (i.e. preferred) species. Furthermore, using the same species for both screening and definite tests could be advantageous, since the screen will serve as a range finder for higher tier testing. For instance, for fish screening tests there is a de facto preference for fathead minnow, at least for substances that are globally assessed, due to specification for the US-EPA endocrine disrupter screening program (US EPA, 2011). In contrast, for higher tier fish full life-cycle tests, medaka has emerged as the preferred species because of its size, shorter generation time and genotypic sex markers enabling the same endpoints to be determined with fewer individuals and with higher certainty than with other species. This conflict has already been acknowledged as an issue by the OECD fish toxicity testing framework (OECD, 2012b).

Standard long-term toxicity assays: Long-term toxicity tests are already performed (typically OECD 210 fish early life-stage tests) in the standard assessment of substances (e.g., to provide chronic fish toxicity data for EU REACH registrations). It is recognised that the relevance of this test could be enhanced by inclusion of additional endpoints. For example, there is potential for taking histopathological and/or tissues samples for biomarker analysis, if there were any concerns (e.g. from structural alerts) that the substance could possess endocrine disruption properties. Clearly there would be animal welfare and cost benefit issues, if multiple questions could be addressed without the need for additional animal testing.

Duplication of endpoints: At the screening tiers, there are two clearly defined key tests: the fish screening tests and the amphibian metamorphosis assay which address different endocrine axes, i.e. the hypothalamic-pituitary-gonadal and the hypothalamicpituitary-thyroid axis. However, at higher tier testing, there is overlap of endpoints (e.g. sexual development) in the fish and amphibian assays. Given the conserved nature of the vertebrate endocrine system, there may be an opportunity to start with only one higher tier test and only in case of non-conclusive results consider a 2 nd higher tier test to address any concerns identified at the screening stage.

Numbers of generations: Currently, there is also a debate on the number of generations required for higher tier studies such as the fish full life-cycle test. There is no indication that there is a need for addressing more than two and - similar as in the field of human hazard assessment - extended 1-generation reproduction tests could supersede multiple generation tests (Spielmann and Vogel, 2007; OECD, 2012c).

\subsubsection{Limitations and research needs of alternative approaches in endocrine disruption}

The regulatory consequences of a substance being considered (identified or classified) an EDC are high, and, therefore, there is significant pressure to provide definitive answers to address any potential EDC concerns. Apart from general limitations of alternative test systems (see Section 6) sensitive target organs such as gonads are not addressed by cellular assays or are in a very early stage of differentiation in fish and amphibian embryos. As a consequence, the use of vertebrate higher tier tests is at present preferred also at the screening level. The US-EDSP will present a unique and invaluable source of information to evaluate the performance of the tier 1 in vitro tests and provide data to enable test design optimisation to accommodate animal welfare considerations. In fact, this is part of the intent of the US-EPA as it drives forward to develop the next generation of assays as a part of its EDSP 21 programme, placing greater emphasis on using computational or in silico models and molecular-based in vitro highthroughput (HTP) assays to prioritise and screen chemicals (US EPA, 2011). An intermediate solution might be that the in vitro test battery is applied in combination with conventional approaches, to reassure regulatory authorities (Scholz et al., 2013).

There is a clear need for a systematic approach as suggested above to provide a battery of existing or desired in vitro assays for biologically relevant endpoints of known mechanisms for EDCs. For a number of known EDCs the responses of this battery of tests should be compared to the already existing in vivo assays. The comparison of predicted and determined in vivo effects will identify research gaps and needs, before a battery of test methods can be advised for a tiered approach with triggers for labelling a compound as an EDC with low or high concern. In case of the latter the compound would be a candidate for further investigation. Ultimately, practical experience during regulatory programmes (e.g. US-EPA EDSP) will inform on the applicability domains and constraints of such approaches and indicate areas for reduction of animal use.

\subsection{Bioaccumulation}

Bioaccumulation is defined as the biological sequestering of xenobiotics and/or their metabolites by uptake via food, water, air, or sediment, such that the concentration in the organism is greater than that in its surroundings or food. Bioaccumulation is the result of absorption, distribution, metabolism, and excretion processes within the organism. Since the United Nations Stockholm Convention on persistent organic pollutants (POPs) was adopted in 2001, there has been significant activity concerning the assessment of persistent, bioaccumulative, toxic (PBT) substances worldwide. Current regulations for industrial chemicals, plant protection products, biocidal products and pharmaceuticals require testing for the bioaccumulation potential by estimating a bioconcentration factor (BCF) in aquatic organisms. The requirement for BCF estimation in legislation is driven by certain criteria, such as production volumes and/or hydrophobicity (as described by the chemical's $\log K_{\text {ow }}$ ). For example, the European REACH regulation requires chemical substances produced above 100 tons/year to be evaluated for their potential to bioaccumulate in the environment. This requirement is contingent upon the $\log K_{o w}$ being $\geqslant 3$ (Table 1). In order to avoid unnecessary testing on animals, $\mathrm{REACH}$ requests the use of existing information from standard and nonstandard methods, in vitro methods, in silico methods, read-across, and weight-of-evidence in an integrated testing strategy for assessing the bioaccumulative potential of a substance. Despite this, a recent ECHA review (see Section 3, ECHA, 2011) reveals that still $42 \%$ of the recently submitted REACH dossiers for chemicals produced over 1000 tons/year ( $\sim 1500$ chemicals) contained bioac- 
cumulation data based on in vivo tests with fish (e.g., OECD TG 305, OECD, 2012f).

There is a clear need to develop alternative methods for evaluating the bioconcentration of the thousands of chemicals that will need to be assessed over the next few years, taking into account integrated testing strategies and a tiered, weight-of-evidence approach. These alternatives may include enhancement of modeling approaches, use of cellular or fish embryo test systems, refinement of in vivo methods, solid phase microextraction (SPME) and potential combination of assays to address active transport and metabolic processes. The use of SPME has been suggested as an approach to 'biomimic' bioconcentration and has been recognised by OSPAR (OSPAR, 2007) and under REACH (ECHA, 2008c) as a technique which can give an initial estimate of bioaccumulation potential of components of effluents and multi constituent substances.

Currently, determination of the BCF is performed according to the OECD TG 305 (OECD, 2012f). Overall, this method is timeand cost-intensive, and the basic protocol requires a minimum of 108 fish per chemical. The guideline was recently revised, and major changes include the ability to test at a single concentration, if it is anticipated that uptake is not likely to be concentration-dependent. This has been demonstrated to be the case in an analysis of 55 plant protection product active substances indicating a good potential for reduction for pesticides (Creton et al., 2013b). In addition, a "limit test" approach has also been incorporated, which requires a reduced number of sampling points (a minimum of two samples taken during the depuration phase). The BCF calculation is then based on deriving a kinetic BCF (constants of uptake/depuration rate or $\mathrm{k}_{1} / \mathrm{k}_{2}$ ) rather than determining a steady-state BCF (Arnot and Gobas, 2006). This will allow a significant reduction in the number of fish to be used to determine the bioconcentration potential of a substance. Finally, the revised methodology contains a test for dietary exposure, which is proposed for certain groups of substances where aqueous exposure is not suitable. This applies for high $\log K_{o w}$ $(>5.5)$ compounds.

The majority of current alternative, preliminary bioaccumulation assessments rely on QSAR- and $\log K_{\text {ow }}$-based estimates for fish (Arnot and Gobas, 2006) such as the BCFBAFTM program from the Estimation Program Interface (EPI) Suite (US EPA, 2013). These models already consider (estimated) biotransformation rates $\left(\mathrm{k}_{m}\right)$. However, for many chemicals, the existing models may not be valid, outside of the applicability domain and/or do not account sufficiently for the impact of ADME processes in the organism. There is also ongoing work to integrate in vitro methods into QSAR models (e.g., isolated hepatocytes, subcellular fractions, and cell lines) to measure the metabolism of chemicals and to use this information as a key parameter in combination with existing models (Cowan-Ellsberry et al., 2008; Johanning et al., 2001; Baron et al., 2012; Nichols et al., 2006; Nichols et al., 2013). Nichols et al. (2006, 2013) created a physiologically based toxicokinetic (PBTK) model for fish, where in vivo metabolism rates are extrapolated from intrinsic in vitro clearance rates. For the determination of intrinsic clearance, fish liver S9 fractions or microsomes can be used. These fractions are enriched in phase I metabolising enzymes and some phase II conjugation enzymes (Weisbrod et al., 2009) and mimic the hepatic in vivo metabolism. Furthermore, existing and recently generated in vivo data are being analysed to incorporate chemical dietary uptake efficiency into bioaccumulation estimation models (Parkerton et al., 2012).

Quantification of internal doses may provide a key to calculate BCFs in alternative test systems (such as embryos, larvae, or cell culture). However, bioconcentration test designs require exposure of cells and embryos to non-toxic, i.e. comparatively low chemical concentrations. Chemical analysis of these concentrations within small-scale systems is challenging due to the need to reliably quantify low absolute chemical amounts, but is not impossible (e.g. Kühnert et al., 2013;Broeders et al., 2013; Schirmer et al., 1997). The use of radioactively labeled compounds can solve analytical determinations and also provides specificity for parent compounds and transformation products if combined with appropriate analytical separation techniques such as HPLC. However, this approach might be cost-prohibitive and not available to all laboratories. Provided that exposure concentrations are not affected by sorption or volatilisation of test compounds (e.g. by using locked glass vials), BCFs may indirectly be calculated from the reduction kinetic of exposure concentrations in the fish embryo test (Schreiber et al., 2009). This approach was already proposed for the estimation of BCFs using adult fish (Banerjee et al., 1984), but was controversially discussed due to interference with transformation processes (Parkerton et al., 2008). More recently, also an analysis of hydrophobic compounds in zebrafish embryos indicated that internal concentration time courses cannot reliably be predicted from the decline of exposure concentrations (Kühnert et al., 2013).

As there are still a number of areas of uncertainty related to the alternative BCF assessments, the current practice of regulatory authorities is to require in vivo data. The main reason being that the risk of obtaining under-/overestimation of BCFs by using data from alternative test systems is difficult to estimate. One of the key issues with future acceptance of any alternative approach for bioaccumulation/bioconcentration assessment will be how the data are viewed by regulatory authorities to identify PBT compounds (i.e. compounds with high persistence, bioaccumulation and toxicity). For example, if an alternative approach indicates that the bioconcentration potential of a substance is negligible, then it may be considered unnecessary to perform a full fish bioconcentration study or simply the reduced (limit test) approach may be sufficient. Similarly, if the substance is clearly bioaccumulative (B) or very bioaccumulative (vB) (i.e. $B C F>2000$ or $>5000$ ), then it may also not be necessary to perform a full fish bioconcentration test. Similar to other endpoints and alternative approaches, research has to be intensified to identify suitable tests/strategies or amend existing methods with high capacity for successful validation and regulatory acceptance.

\section{Common limitations, perspectives and research needs}

Regardless of the endpoint to be predicted, there are limitations and research needs common to most of the alternative approaches. However, many of these limitations are also linked with promising perspectives for future developments as described below.

\subsection{Mechanism-based approaches}

The sequence of events from chemical structure through molecular initiating events, cellular and organism responses to final adverse effects - formalised in the adverse outcome pathway (AOP) concept (Ankley et al., 2010) - provides the opportunity to identify key events that could be targeted by alternative assays. An example is given by the detailed formulation of the AOP for skin sensitization in human hazard assessment (OECD, 2012a). Correspondingly, AOPs have been proposed for environmental hazard assessment, e.g. for chronic fish toxicity or endocrine disruption (Volz et al., 2011; Kramer et al., 2011; Ankley et al., 2010; Villeneuve et al., 2013). Although the AOP concept has been acknowledged by many scientists, the development of alternative tests will still require proof of concept and ultimately regulatory acceptance of the AOP methodology. Parallel paths are being taken in human safety (e.g., Tox21 by the USEPA; Risk21 under ILSI-HESI) 
(Schmidt, 2009; Kavlock et al., 2007; Dix et al., 2012), which is being broadly supported by OECD. Recently, the Tox 21 framework was used to rapidly test for hazards associated with different oil dispersant options in the oil spill in the Gulf of Mexico in the summer of 2010 by (partially) mechanistic in vitro assay (Judson et al., 2010). Environmental scientists should also take advantage of these opportunities by developing environmental AOP concepts and frameworks with established links between mechanistic and apical endpoints relevant for regulatory decisions on the hazard and risk assessment of chemicals (OECD, 2012e).

A detailed mechanistic understanding can also help to identify potential limitation of alternative approaches, i.e. the identification of the lack of representation of particular modes of action and the ability to model them to the same extent in an alternative approach. This has been partially addressed, for instance for the replacement of the fish acute toxicity test with the FET. An analysis of fish embryo acute toxicity data by Knöbel et al. (2012) and of fish gill cell line viability data by Tanneberger et al. (2013) indicated that some outliers could be related to the mechanism of action (see also Section 5.1). Appropriate modifications of the test setup were suggested to help overcome these limitations but further research is required to establish these and prove their effectiveness. Inclusion of MoA-targeted assays such as investigation neurotoxicity by behavioural analyses (Kokel et al., 2010; Selderslaghs et al., 2013), might improve the predictive capacity.

Finally, mechanistic studies such as those conducted in the USEPA ToxCast program should also be evaluated to identify the appropriate key events which can predict adverse effects on the environment.

\subsection{Bioavailability and stability of test concentrations}

Limitations of alternative test systems can also be associated with the exposure design. For instance, plastic multi-well plates commonly used in cell- and embryo-based test systems may adsorb lipophilic compounds $\left(\log K_{o w} \geqslant\right.$ ca. 3 ). This can affect exposure concentrations, particularly with chemicals that are poorly water soluble. Volatilisation from exposure vessels can also contribute to significant losses of test compounds (Riedl and Altenburger, 2007; Schreiber et al., 2008; Tanneberger et al., 2010). In cell culture systems, binding to medium ingredients (serum proteins) may additionally reduce the bioavailable concentration of the compound (Kramer et al., 2009; Schirmer et al., 1997). Test setups that ensure stable exposure concentrations over the test duration are required to ensure that difficult-to-handle compounds, i.e. those with high volatility or hydrophobicity can be properly assessed. Potential test set ups may include flow-through designs (Lammer et al., 2009b) or passive dosing (Kramer et al., 2010; Smith et al., 2010; Smith et al., 2009; Brown et al., 2001). In the passive dosing approach, the chemical partitions into the medium from a biologically inert polymer previously loaded with the chemical. This technique enables maintenance of a stable exposure concentration and has been applied for a range of biological tests where exposures were performed in plastic multi-well plates. However, this technique is currently very labour-intensive, and no standard operation procedures are available. Alternatively, the compound loss through sorption and volatilization can be corrected through an empirical relationship with hydrophobicity and Henry's law constant (Schramm et al., 2011), provided an appropriate model can be derived for the in vitro system of interest and with a reasonable work load.

Until relatively recently, exposure concentrations were rarely analysed in cell culture or embryo tests and hence, effect concentrations were calculated based on nominal (intended) concentrations. However, analytical verification of exposure concentration is already required and routinely applied for in vivo tests and has been implemented in the recently approved TG 236 for the Fish Embryo Acute Toxicity Test (OECD, 2013). It can be expected that the determination of effect concentrations based on measured concentrations will improve the predictive capacity of alternative test systems (Knöbel et al., 2012; Tanneberger et al., 2013).

\section{3. $A D M E$}

Significant differences in ADME (absorption, distribution, metabolism and excretion) properties can be considered as major limitation of alternative test systems, since they impact on the internal concentration, the chemical concentrations at the target site (s). This applies in principal to both in vitro and embryo tests. However, it is anticipated that as primary cells and embryos more closely resemble adult animals or intact organs, these should provide more similar metabolic properties than systems based on permanent cell cultures. In the case that in vitro-in vivo differences of ADME are of minor relevance for the internal concentration, alternative test systems may provide a high confidence for predicting the in vivo effect. For example, in the testing for skin or eye irritation required in human hazard assessment significant ADME effects are limited by the direct application of the test agent at its target site in vivo (Leist et al., 2012). For other applications, ADME differences need to be considered more carefully, e.g. by a detailed characterisation of uptake and metabolism. For zebrafish embryos, for instance, it was shown that $A B C$ efflux transporter are active in early developmental stages and able to reduce the uptake of chemicals (Fischer et al., 2013). Furthermore, transcriptional profiling of zebrafish embryos has indicated that the majority of their cytochrome P450 biotransformation enzymes are already expressed and at least partially active during embryonic development (Goldstone et al., 2010; Weigt et al., 2011, 2012). Furthermore, the activity of metabolic enzymes is enhanced in fish embryos exposed to chemicals (e.g. González-Doncel et al., 2011; Noury et al., 2006). For primary fish hepatocytes and fish cell lines, some research has been undertaken to characterise xenobiotic transport and metabolising potencies (e.g. Escher et al., 2011; Thibaut et al., 2009; Fischer et al., 2011). However, further research is needed to fully understand the active transport and metabolic capacity of in vitro alternatives and potential implications for the prediction of toxic effects.

In case where there is a potential lack of relevant metabolic capacities in alternative test systems, these can be combined with a metabolic activation system (Busquet et al., 2008; Weigt et al., 2010), such as liver microsomal preparations from an S9 extract (i.e. the supernatant of a liver homogenate). Incubation with metabolic activation systems may also lead to the identification of potential metabolites, an example of which is shown e.g. for hydroxylation of brominated flame retardants (Hamers et al., 2008). In such cases, synthesis of the metabolites could be performed in vitro to account for the potential effect of biotransformation on toxicity or accumulation (Montaño et al., 2012), to prevent underestimation of the hazard. The identification of metabolites may, however, also indicate that the compound could be readily inactivated and/or excreted by biotransformation. Moreover, computational methods such as those included in the OECD QSAR toolbox (http://www.qsartoolbox.org) can contribute by identifying potential metabolites which could be included in in vitro testing to account for a potential limited metabolic capacity of the alternative test system.

Understanding of ADME is also highly relevant for predicting the bioconcentration or diffusion of chemicals in alternative approaches. Metabolism is a mitigating process, generally leading to production of more water-soluble metabolites and enhanced elimination of the toxicant from the exposed organism and 
resulting in a lower BCF and/or effect concentrations. Hence, differences in metabolising and xenobiotic transport capacities of cultured cells and fish embryos compared to adult fish must be taken into account when using these alternative models. Another consideration for highly lipophilic substances is that uptake may be underestimated due to different lipid concentrations present in cells versus whole organisms. Furthermore, the role of transporter proteins for bioconcentration in vivo and in vitro is not well understood (Epel et al., 2008), and cellular uptake and elimination by active transport may result in discrepancies of bioconcentration and effect concentrations in vivo and in alternative experimental test systems. For instance, $A B C$ transporter expression and activity levels differ between permanent fish cell lines and the tissue these cell lines were derived from (Fischer et al., 2011). Discrepancies between fish embryos and later life stages may result from interference by the yolk. It was shown that very lipophilic compounds concentrate in the yolk sac leading to higher internal exposure while compounds with $\log K_{o w}<5$ disappear faster from the larvae than expected by diffusion and hence, leading to lower than expected tissue residues (Foekema et al., 2012).

The extrapolation of responses measured in vitro to those seen in vivo would principally requires knowledge of the actual chemical concentrations at the target sites, which is usually not measured neither in vivo nor in vitro. Fortunately, as indicated by the high correlation of fish embryos and fill cell lines with acute fish toxicity, the internal target site concentrations can be expected to be similar for many compounds. This could be anticipated given similar exposure pathways based on a partition equilibrium with an aqueous test medium. However, this is not a reason to be complacent and internal concentration analysis is recommended to help to identify compounds for which the fish embryo or cell lines may underestimate the acute toxicity. In addition, support of pharmacokinetic models, prediction of internal concentrations could provide a framework to improve the in vitro-in vivo link. This has been successfully performed with the extrapolation of in vitro estrogenicity values to in vivo effects by including ADME parameters determined in vitro as well (Punt et al., 2013). Furthermore, a detailed toxicokinetic/pharmacokinetic understanding and appropriate PBPK modelling can also contribute to the reduction of animal test numbers, if in vivo models are continued to be used (i.e. by providing a better estimation of the concentrations likely causing an effect, the number of test concentration could be reduced).

\subsection{Validation}

Once an alternative approach has been demonstrated to provide a promising predictive capacity and to be scientifically relevant, the major limiting step for developing an OECD guideline and its wider application is its validation. The fish embryo acute toxicity test provides an appropriate example. The excellent correlation to acute fish toxicity was long known (Nagel, 2002). However, only recently, after a validation study had been successfully completed (OECD, 2012g), an appropriate testing guideline of the Fish Embryo Acute Toxicity Test (FET) has been adopted by the OECD (OECD TG 236). For the area of environmental risk assessment, the FET is the only alternative method that has successfully been validated. This may be set to change as a recent study has demonstrated that the use of a fish gill cell line for testing acute fish toxicity is scientifically relevant and after optimisation (e.g. bioavailability in cell cultures, role of the mode of action and physico-chemical properties of test compounds, correlation between cell $\mathrm{EC}_{50}$ and fish $\mathrm{LC}_{50}$ ), the test is now ready to proceed to validation (Tanneberger et al., 2013).

Validation is not always essential as this may not be needed for the use of an alternative test method in a weight-of-evidence approach. However, it is required for its development into an OECD test guideline or other specific regulatory test guidelines (see Text Box 2 on validation of alternative methods for details). The validation process could delay the adoption of an OECD guideline, if results on robustness, intra- and inter-laboratory calibration studies do not provide enough confidence in the method.

\section{Validation of alternative methods}

Alternative testing methods and strategies can be used and accepted without validation - at least within a weightof-evident approach. However, for an international mutual acceptance for hazard identification and risk assessment, successful validation and subsequent adoption as OECD test guideline are considered mandatory. The validation process provides evidence for the reliability and relevance of the approach with respect to a particular purpose. Depending on the type of test method developed (in vitro, OSAR, 'omics'based, etc.), specific requirements are applicable. Various organisations (e.g. OECD and EURL ECVAM) have provided guidance documents on validation principles for new test approaches in hazard assessment (OECD, 2007a, 2005; Curren et al., 1995; Balls et al., 1995; Hartung et al., 2004). The OECD has outlined these principles - also known as SOLNA principles (OECD, 1996) - as follows:

(1) The rationale for the test method should be available.

(2) The relationship between the test method's endpoint(s) and the (biological) phenomenon of interest should be described.

(3) A detailed protocol for the test method should be available.

(4) The intra- and inter-laboratory reproducibility of the test method should be demonstrated.

(5) Demonstration of the test method's performance should be based on the testing of reference chemicals representative of the types of substances for which the test method will be used.

(6) The performance of the test method should have been evaluated in relation to the relevant information from the species of concern and existing relevant toxicity testing data.

(7) Ideally, all data supporting the validity of a test method should have been obtained in accordance with the principles of GLP.

All data supporting the assessment of the validity of the test method should be available for expert review.

Due to the early stage of the development of experimental alternative approaches to chronic toxicity tests, a validation of potential alternatives is not foreseen at present. It is hoped that perspective candidate assays for validation will probably evolve from the AOP research where there is emphasis on finding key endpoints which will provide sufficient predictive capacity for higher organism in vivo effects. This would lead to the development of AOP-targeted alternative test systems (Hartung et al., 2013a). However, the AOP concept differs fundamentally from 
traditional test designs using whole organisms and apical endpoints and, hence, validation schemes require adaptation to this concept.

Validation schemes for non-testing approaches have already been proposed (OECD, 2007a), but they still need to be improved. This is especially true for standardized reporting, where clear guidance and/or recommendations with regard to the new OECD guidelines are needed (OECD, 2007a). Validation may also be a problem for some particular QSAR models which are incorporated into complex existing tools such as ECOSAR. Such an integration does not allow proper access to individual QSARs and their appropriate validation on an individual basis (Kaiser et al., 1999).

Given the relevance of validation for regulatory acceptance, aspects of validation should be considered early in the development of alternative assays in order to accelerate potential subsequent validation. It is, therefore, important to instruct scientists involved in the development of alternatives and acquaint them with validation needs. Protagonists of methods should also include the concept of 'applicability domains' so that the limitations of a particular alternative method are identified at the outset. A critical observation is that research funding schemes in Europe and worldwide usually do not support validation studies for alternative tests. This may partially explain the long time period between the initial development of an alternative approach and its final validation. Validation can be time-consuming, costly and generally requires voluntary participation and internal resources from participants. It appears that the missing link once alternatives have been developed still remains the step between proof of concept and validation. It is obvious that there is a need to find mechanisms to help fund and thereby speed up the validation of promising alternative test methods. Also, until validated and harmonised testing protocols are available, alternative testing approaches should at least be used in weight-of-evidence perspective.

\subsection{Availability of reference in vivodata}

Availability of high quality in vivo data has been identified as one of the major limitations, since these are required as a training set or to be used as benchmarks both in the development and validation phases to demonstrate the credibility of alternative testing approaches (experimental and non-testing). Increasing the availability and/or facilitating the access to existing in vivo toxicity data can be considered as a prime action to foster the development and application of alternatives.

The acute fish toxicity test provides an example of how the availability of a curated and validated data base for one species the fathead minnow - including more than 630 compounds has supported the development of various alternative experimental and non-testing methods (Russom et al., 1997; Lammer et al., 2009b; Tanneberger et al., 2013; Schüürmann et al., 2011). For chronic effects, however, such a database does not currently exist. Some initiatives have been taken to try and redress this problem. For example there are published evaluations of fish early life-stage toxicity data which have been based on a coded set of proprietary compounds for which appropriate information has been provided during their registration or was provided by industry to a contract researcher (Ahlers et al., 2006; Oris et al., 2012). However, if high quality data are not publicly available and non-coded, it is difficult to identify outliers and improve the models. Some approaches, however, such as the Threshold (Step-Down) Approach for the reduction of acute fish toxicity tests can be already sufficiently evaluated with coded data sets (Jeram et al., 2005).

High quality data already exists at least partially, e.g. in the ECHA, EFSA (European Food Safety Authority) or EMA (European Medicines Agency) dossiers provided for the registration of chemicals, plant protection products and pharmaceuticals. Recently, the
OECD and ECHA have jointly developed a web-based search tool to facilitate access and search of REACH dossier data (Wittwehr, 2011, http://www.echemportal.org). Furthermore, other databases such as the US-EPA ECOTOX database are linked to the eChemPortal. Also, ECETOC (2013) is compiling REACH dossier data into a database, and EFSA makes information on PPPs available. ${ }^{38}$ These tools and databases are expected to greatly facilitate the establishment of animal test benchmarks for the development of alternative testing strategies. However, despite the principal availability, the data are usually not provided in an appropriately structured database format. Furthermore, data summaries are provided but in order to fully explore the data for development of alternative testing strategies access to raw data ideally via extended, uniform sets of toxicity data (e.g. from registration dossiers of industry) in a user-friendly format would be needed. If an analysis of existing data revealed a significant restriction of access due to intellectual property rights, a potential revision of international regulations aiming at facilitating data access might be considered. For instance, data should be made accessible at least for approved governmental organisations or public research institutions, if needed through a broker to mitigate concerns around commercial sensitivity. Experience has shown that use of an 'honest broker' to facilitate data sharing, but maintain confidentiality, can be acceptable to academic and industrial partners and can enable the development of an evidence base to support arguments for changes in practice (Robinson et al., 2008; Chapman et al., 2012; Chapman et al., 2010; Chapman et al., 2009; Oris et al., 2012). A further possibility is to restrict the use of in silico tools such as the software SARpy (Ferrari et al., 2013) on in-house data. In this way industry does not need to disclose the structures of confidential substances and toxicity values but can provide the model, i.e. a set of rules, like structural alerts. These rules can be used without disseminating the structures.

Finally, it should be recognised that variability and poor experimental design of currently conducted in vivo assays may confound the estimation of the predictive capacities of alternative approaches. Therefore, improvement and refinement of existing animal test design would also indirectly contribute to progress on the development of alternative assays.

\section{General conclusions}

There are various areas in the development of alternative testing approaches in environmental hazard and risk assessment that require future action and research. As outlined above, they appear to apply to many endpoints, regardless of whether testing or nontesting approaches are considered. These include the need for a detailed mechanistic understanding, e.g. for the exploitation of the AOP concept, as well as knowledge on bioavailability and ADME of chemicals in vivo and in vitro. However equally important for the development of alternatives is the availability of high quality in vivo reference data. For the final acceptance of a scientifically valid approach, successful validation and availability of internationally accepted test guidelines is a prerequisite.

It is now generally accepted that it is difficult to replace an animal test by a single experimental or non-testing approach. Therefore, ITS can provide the operational means to combine the different promising alternative methods in a powerful and predictive approach that allows significant reduction of animal testing. To achieve this goal it will be necessary to develop formalised ITSs that allow industry and regulators to provide potential hazard information with high reliability with at least the confidence of a vertebrate test or endpoint.

\footnotetext{
$\overline{38}$ The EFSA conclusions on pesticides are freely available via the EFSA webpage http://www.efsa.europa.eu/en/publications.htm. More details are available on request via the Draft Assessment Reports.
} 
Finally, a serious problem in the implementation of alternatives approaches in environmental risk assessments arises from the fact that discussions about alternatives are frequently based upon 'perceptions' and not exclusively based on scientific arguments. The problem is that such perceptions may interfere with an objective discussion of pros and cons of various alternative approaches. The best (and only) option to overcome emotions and conservatism are, of course, an even more convincing outcome from validation projects and more striking scientific arguments. Moreover, continuous information and education of a broad public including academics, industry and regulators is required to create a better understanding of the opportunities and potential applicability of new alternative methods. If a broad consensus on these issues cannot be achieved, the future for widespread adoption of alternative approaches in environmental risk assessment will remain an admirable, but distant goal.

\section{Disclaimer}

This manuscript has been subjected to review by the US EPA. The views, conclusions and recommendation expressed in this article are those of the authors and do not necessarily represent views or policies of the US EPA, the European Commission or the German Federal Environmental Agency (UBA) and other organisations to which authors are affiliated.

\section{Conflict of interest}

The authors declare that there are no conflicts of interest.

\section{Acknowledgments}

This review was stimulated by an expert meeting held in October 2011 at the Helmholtz Centre for Environmental Research UFZ, Leipzig, Germany, with about 40 international experts with a background in research, industry or regulation. The meeting was organized and supported by EUROECOTOX, a coordination action funded within the European Commission 7th Framework Programme (Grant agreement no 265.260). The aim of this meeting was to discuss the perspectives of alternatives to animal tests in environmental risk assessment.

We acknowledge critical reading and commenting of the article by François Busquet, CAAT (Centre for Alternatives to Animal Testing) Europe, Brussels, Belgium, Adela Lopez Cerain, ECOPA (European consensus-platform on alternatives), and for Section 3 by Hannu Braunschweiler, European Chemical Agency, Helsinki, Finland. Stephanie Bopp (EFSA, Parma, Italy) is acknowledged for providing information on availability and access to pesticide toxicity information at EFSA. Furthermore, we would like to thank the anonymous reviewers for their helpful comments and suggestion to improve the article.

\section{References}

Ahlers, J., Riedhammer, C., Vogliano, M., Ebert, R.-U., Kühne, R., Schüürmann, G. 2006. Acute to chronic ratios in aquatic toxicity-variation across trophic levels and relationship with chemical structure. Environ. Toxicol. Chem. 25, 29372945.

Ankley, G.T., Bennett, R.S., Erickson, R.J., Hoff, D.J., Hornung, M.W., Johnson, R.D. Mount, D.R., Nichols, J.W., Russom, C.L., Schmieder, P.K., Serrrano, J.A., Tietge, J.E., Villeneuve, D.L., 2010. Adverse outcome pathways: a conceptual framework to support ecotoxicology research and risk assessment. Environ. Toxicol. Chem. 29, 730-741.

Anselmo, H.M.R., 2012. Effects of marine persistent organic pollutants on rarely life development and metamorphosis of echinoids. PhD thesis, Wageningen University. Fulltext available at http://edepot.wur.nl/2410224.

Anselmo, H.M.R., Koerting, L., Devito, S., van den Berg, J.H.J., Dubbeldam, M. Kwadijk, C., Murk, A.J., 2011. Early life developmental effects of marine persistent organic pollutants on the sea urchin Psammechinus miliaris. [Corrigendum published in Ecotoxicol. Environ. Saf. 74 (2011) 2182-2192]. Ecotoxicol. Environ. Saf. 74, 2182-2192.

Archer, G., Balls, M., Bruner, L.H., Curren, R.D., Fentem, J.H., Holzhütter, H.G., Liebsch, M., Lovell, D.P., Southee, J.A., 1997. The validation of toxicological prediction models. ATLA 25, 505-516.

Arnot, J.A., Gobas, F.A., 2006. A review of bioconcentration factor (BCF) and bioaccumulation factor (BAF) assessments for organic chemicals in aquatic organisms. Environ. Rev. 14, 257-297.

Balls, M., Amcoff, P., Bremer, S., Casati, S., Coecke, S., Clothier, R., Combes, R., Corvi, R., Curren, R., Eskes, C., 2006. The principles of weight of evidence validation of test methods and testing strategies: the report and recommendations of ECVAM workshop 58a. ATLA. 34, 603.

Balls, M., Blaauboer, B.J., Fentem, J.H., Bruner, L., Combes, R.D., Ekwall, B., Fielder, R.J., Guillouzo, A., Lewis, R.W., Lovell, D.P., 1995. Practical aspects of the validation of toxicity test procedures - the report and recommendations of ECVAM workshop 5. ATLA 23, 129-147.

Banerjee, S., Sugatt, R.H., O'Grady, D.P., 1984. A simple method for determining bioconcentration parameters of hydrophobic compounds. Environ. Sci. Technol. $18,79-81$.

Baron, M.G., Purcell, W.M., Jackson, S.K., Owen, S.F., Jha, A.N., 2012. Towards a more representative in vitro method for fish ecotoxicology: morphological and biochemical characterisation of three-dimensional spheroidal hepatocytes. Ecotoxicology 21, 2419-2429.

Bars, R., Broeckaert, F., Fegert, I., Gross, M., Hallmark, N., Kedwards, T., Lewis, D., O'Hagan, S., Panter, G.H., Weltje, L., Weyers, A., Wheeler, J.R., Galay-Burgos, M. 2011. Science based guidance for the assessment of endocrine disrupting properties of chemicals. Regul. Toxicol. Pharmacol. 59, 37-46.

Bars, R., Fegert, I., Gross, M., Lewis, D., Weltje, L., Weyers, A., Wheeler, J.R., Galay-Burgos, M., 2012. Risk assessment of endocrine active chemicals: Identifying chemicals of regulatory concern. Regul. Toxicol. Pharmacol. 64, $143-154$.

Belanger, S.E., Rawlings, J.M., Carr, G.J., 2013. Use of fish embryo toxicity tests for the prediction of acute fish toxicity to chemicals. Environ. Toxicol. Chem. 32, 17681783.

Beresford, N., Routledge, E.J., Harris, C.A., Sumpter, J.P., 2000. Issues arising when interpreting results from an in vitro assay for estrogenic activity. Toxicol. Appl. Pharmacol. 162, 22-33.

Blackburn, K., Bjerke, D., Daston, G., Felter, S., Mahony, C., Naciff, J., Robison, S., Wu, S., 2011. Case studies to test: a framework for using structural, reactivity, metabolic and physicochemical similarity to evaluate the suitability of analogs for SAR-based toxicological assessments. Regul. Toxicol. Pharmacol. 60, 120135.

Blaschke, U., Eismann, K., Böhme, A., Paschke, A., Schüürmann, G., 2011. Structural alerts for the excess toxicity of acrylates, methacrylates, and propiolates derived from their short-term and long-term bacterial toxicity. Chem. Res. Toxicol. 25, $170-180$.

Böhme, A., Thaens, D., Schramm, F., Paschke, A., Schuüürmann, G., 2010. Thiol reactivity and its impact on the ciliate toxicity of $\alpha, \beta$-unsaturated aldehydes, ketones, and esters. Chem. Res. Toxicol. 23, 1905-1912.

Bols, N.C., Dayeh, V.R., Lee, L.E.J., Schirmer, K., 2005. Use of fish cell lines in the toxicology and ecotoxicology of fish. In: Mohn, T.W., Mommsen, T.P. (Eds.), Biochemistry and Molecular Biology of Fishes, vol. 6. Elsevier Science, Amsterdam, The Netherlands.

Brion, F., Le Page, Y., Piccini, B., Cardoso, O., Tong, S.-K., Chung, B.-c., Kah, O., 2012. Screening estrogenic activities of chemicals or mixtures in vivo using transgenic (cyp19a1b-GFP) zebrafish embryos. PLoS One 7, e36069.

Broeders, J.J.W., Blaauboer, B.J., Hermens, J.L.M., 2013. In vitro biokinetics of chlorpromazine and the influence of different dose metrics on effect concentrations for cytotoxicity in Balb/c 3T3, Caco-2 and HepaRG cell cultures. Toxicol. In vitro 27, 1057-1064.

Brown, R.S., Akhtar, P., Åkerman, J., Hampel, L., Kozin, I.S., Villerius, L.A., Klamer, H.J.C., 2001. Partition controlled delivery of hydrophobic substances in toxicity tests using poly(dimethylsiloxane) (PDMS) films. Environ. Sci. Technol. 35, 4097-4102.

Buist, H., Aldenberg, T., Batke, M., Escher, S., Kühne, R., Marquart, H., Pauné, E., Rorije, E., Schüürmann, G., Kroese, D., 2013. The OSIRIS Weight of Evidence approach: ITS mutagenicity and ITS carcinogenicity. Regul. Toxicol. Pharmacol. 67, 171-181.

Busquet, F., Nagel, R., von Landenberg, F., Mueller, S.O., Huebler, N., Broschard, T.H., 2008. Development of a new screening assay to identify proteratogenic substances using zebrafish Danio rerio embryo combined with an exogenous mammalian metabolic activation system (mDarT). Toxicol. Sci. 104, $177-188$.

Carmichael, N., Bausen, M., Boobis, A.R., Cohen, S.M., Embry, M., Fruijtier-Pölloth, C. Greim, H., Lewis, R., Meek, M.E., Mellor, H., Vickers, C., Doe, J., 2011. Using mode of action information to improve regulatory decision-making: an ECETOC/ILSI RF/HESI workshop overview. CRC Cr. Rev. Toxicol. 41, 175-186.

CCAC, 2012. 2010 CCAC Survey of animal use. Available at http://www.ccac.ca.

Chapman, K., Pullen, N., Coney, L., Dempster, M., Andrews, L., Bajramovic, J., Baldrick, P., Buckley, L., Jacobs, A., Hale, G., 2009. Preclinical development of monoclonal antibodies: Considerations for the use of non-human primates. MAbs 1, 505.

Chapman, K.L., Andrews, L., Bajramovic, J.J., Baldrick, P., Black, L.E., Bowman, C.J., Buckley, L.A., Coney, L.A., Couch, J., Maggie Dempster, A., de Haan, L., Jones, K., Pullen, N., de Boer, A.S., Sims, J., Ian Ragan, C., 2012. The design of chronic 
toxicology studies of monoclonal antibodies: implications for the reduction in use of non-human primates. Regul. Toxicol. Pharmacol. 62, 347-354.

Chapman, K.L., Pullen, N., Andrews, L., Ragan, I., 2010. The future of non-human primate use in mAb development. Drug Discov. Today 15, 235-242.

ChemProp, 2012. Chemical Properties Estimation Software System 5.2.7, 2012. Department of Ecological Chemistry. Available for download at http:// www.ufz.de/index.php?en=6738.

COHIBA, 2010. Whole effluent assessment (WEA) proposed recommendations for the use of toxicity limits. Available at http://www.cohiba-project.net.

Collins, F.S., Gray, G.M., Bucher, J.R., 2008. Transforming environmental health protection. Science 319, 906-907.

Cowan-Ellsberry, C.E., Dyer, S.D., Erhardt, S., Bernhard, M.J., Roe, A.L., Dowty, M.E. Weisbrod, A.V., 2008. Approach for extrapolating in vitro metabolism data to refine bioconcentration factor estimates. Chemosphere 70, 1804-1817.

Crane, M., Gross, M., Matthiessen, P., Ankley, G.T., Axford, S., Bjerregaard, P., Brown, R., Chapman, P., Dorgeloh, M., Galay-Burgos, M., 2010. Multi-criteria decision analysis of test endpoints for detecting the effects of endocrine active substances in fish full life cycle tests. Integr. Environ. Assess. Manag. 6, 378-389.

Creton, S., Clook, M., Wheeler, J.R., 2013a. Application of the threshold approach for acute fish toxicity testing to plant protection products: a proposed framework. Chemosphere (accepted for publication).

Creton, S., Douglas, M., Wheeler, J.R., Hutchinson, T.H., 2010. Challenging the requirement for chronic fish toxicity studies on formulated plant protection products. Toxicol. Lett. 199, 111-114.

Creton, S., Weltje, L., Hobson, H., Wheeler, J.R., 2013b. Reducing the number of fish in bioconcentration studies for plant protection products by reducing the number of test concentrations. Chemosphere 90, 1300-1304.

Crump, D., Chiu, S., Gauthier, L.T., Hickey, N.J., Letcher, R.J., Kennedy, S.W., 2011. The effects of Dechlorane Plus on toxicity and mRNA expression in chicken embryos: a comparison of in vitro and in vivo approaches. Comp Biochem Phys C 154, 129-134.

CTGB, 2013. Evaluation Manual for the Authorisation of Plant Protection Products and Biocides According to Regulation (EC) No. 1107/2009. Board for the Authorisation of Plant Protection Products and Biocides. Available at http:www.ctgb.agro.nl.

Curren, R.D., Southee, J.A., Spielmann, H., Liebsch, M., Fentem, J.H., Balls, M., 1995. The role of prevalidation in the development, validation and acceptance of alternative methods. ATLA 23, 211-211.

de Wolf, W., Siebel-Sauer, A., Lecloux, A., Koch, V., Holt, M., Feijtel, T., Comber, M., Boeije, G., 2005. Mode of action and aquatic exposure thresholds of no concern. Environ. Toxicol. Chem. 24, 479-485.

De Zwart, D., 2002. Observed regularitis in species sensitivity distributions for aquatic species. In: Posthuma, L.T.T., Suter, G.W., II (Eds.), Species Sensitivity Distribution in Ecotoxicology. Lewis Publishers, Boca Raton, Florida, pp. 133154.

Dimitrov, S., Dimitrova, G., Pavlov, T., Dimitrova, N., Patlewicz, G., Niemela, J., Mekenyan, O., 2005. A stepwise approach for defining the applicability domain of SAR and QSAR models. J. Chem. Inf. Model. 45, 839-849.

Dix, D.J., Houck, K.A., Judson, R.S., Kleinstreuer, N.C., Knudsen, T.B., Martin, M.T., Reif, D.M. Richard, A.M. Shah, I. Sipes, N.S., Kavlock, RJ. 2012. Incorporating biological, chemical and toxicological knowledge into predictive models of toxicity. Toxicol. Sci., 130.

ECETOC, 2007. Intelligent testing strategies in Ecotoxicology: mode of action approach for specifically acting chemicals. Technical Report No. 102, ISSN0773-8072-102. Available at http://www.ecetoc.org.

ECETOC, 2013. Activity based relationships for aquatic ecotoxicology data: use of the activity approach to strengthen MoA predictions. Technical Report 120 (in press).

ECHA, 2008a. Guidance on Information Requirements and Chemical Safety Assessment - Chapter R.6: QSARs and Grouping of Chemicals. European Chemicals Agency. Available at http://echa.europe.de.

ECHA, 2008b. Guidance on Information Requirements and Chemical Safety Assessment - Chapter R.7b: Endpoint Specific Guidance. European Chemicals Agency. Available at http://echa.europe.de.

ECHA, 2008c. Guidance on Information Requirements and Chemical Safety Assessment Chapter R.11: PBT Assessment. European Chemicals Agency. Available at http://cha.europe.eu.

ECHA, 2010a. Practical guide 2: How to Report Weight of Evidence. European Chemicals Agency. Available at http://echa.europa.eu.

ECHA, 2010b. Practical Guide 4: How to Report Data Waiving. European Chemicals Agency. Available at http://echa.europa.eu.

ECHA, 2010c. Practical Guide 6: How to Report Read-across and Categories. European Chemicals Agency. Available at http://echa.europa.eu.

ECHA, 2011. The Use of Alternatives to Testing on Animals for the REACH Regulation 2011. European Chemicals Agency, ECHA-11-R-004.2-EN, ISBN: 978-92-9503596-6. Available at http://echa.europa.eu.

ECHA, 2012. Experts Workshop on Read-Across Assessment. Background paper: An Introduction to the Assessment of Read-Across in ECHA. European Chemicals Agency, 8 pp. Available at http://echa.europe.eu.

EMA/CHMP, 2006. Guideline on the Environmental Risk Assessment of Medicinal Products for Human Use. EMEA/CHMP/SWP/4447/00. European Medicines Agency. Availabe at www.ema.europe.eu.

EMA/CVMP, 2008. Revised Guideline on Environmental Impact Assessment for Veterinary Medicinal Products in Support of the VICH Guidelines GL6 AND GL 38. EMEA/CVMP/ERA/418282/2005-Rev.1. European Medicines Agency. Available at http://www.ema.europe.eu.
Embry, M.R., Belanger, S.E., Braunbeck, T.A., Galay-Burgos, M., Halder, M., Hinton, D.E., Léonard, M.A., Lillicrap, A., Norberg-King, T., Whale, G., 2010. The fish embryo toxicity test as an animal alternative method in hazard and risk assessment and scientific research. Aquat. Toxicol. 97, 79-87.

Epel, D., Luckenbach, T., Stevenson, C.N., Macmanus-Spencer, L.A., Hamdoun, A., Smital, T., 2008. Efflux transporters: newly appreciated roles in protection against pollutants. Environ. Sci. Technol. 42, 3914-3920.

Escher, B.I., Cowan-Ellsberry, C.E., Dyer, S., Embry, M.R., Erhardt, S., Halder, M., Kwon, J.H., Johanning, K., Oosterwijk, M.T.T., Rutishauser, S., 2011. Protein and lipid binding parameters in rainbow trout (Oncorhynchus mykiss) blood and liver fractions to extrapolate from an in vitro metabolic degradation assay to in vivo bioaccumulation potential of hydrophobic organic chemicals. Chem. Res. Toxicol. 24, 1134-1143.

EU, 1998. Directive 98/8/EC of the European Parliament and of the Council of 16 February 1998 concerning the placing of biocidal products on the market. OJ. European Union L123, 1-63.

EU, 2000. Directive 2000/60/EC of the European Parliament and of the Council establishing a framework for the Community action in the field of water policy (EU Water Framework Directive). OJ. European Union L327, 1-72.

EU, 2001. Directive 2001/83/EC of the European Parliament and of the Council of 6 November 2001 on the Community code relating to medicinal products for human use. Official J. L311, 0067-0128, 28/11/2001.

EU, 2003. Regulation (EC) No $1831 / 2003$ of the European Parliament and of the Council of 22 September 2003 on additives for use in animal nutrition. OJ European Union L268, 29-43.

EU, 2004. Directive 2004/28/EC of the European Parliament and of the Council of 31 March 2004 amending Directive 2001/82/EC on the Community code relating to veterinary medicinal products. OJ. European Union L136, 58-84.

EU, 2006. Regulation (EC) No 1907/2006 of the European Parliament and of the Council of 18 December 2006 concerning the Registration, Evaluation, Authorisation and Restriction of Chemicals (REACH). OJ European Union L396, 1-849.

EU, 2008a. Commission Regulation (EC) No 429/2008 of 25 April 2008 on detailed rules for the implementation of Regulation (EC) No 1831/2003 of the European Parliament and of the Council as regards the preparation and the presentation of applications and the assessment and the authorisation of feed additives. OJ. European Union L133, 1-65.

EU, 2008b. Council regulation (EC) No 440/2008 of 30 May 2008 laying down test methods pursuant to Regulation (EC) No 1907/2006 of the European Parliament and of the Council on the Registration, Evaluation, Authorisation and Restriction of Chemicals (REACH). OJ. European Union L142, 1-739.

EU, 2009a. Regulation (EC) No 1107/2009 of the European Parliament and of the Council of 21 October 2009 concerning the placing of plant protection products on the market and repealing council directives 79/117/EEC and 91/414/EEC. OJ. European Union L309, 1-50.

EU, 2009b. Regulation (EC) No 1223/2009 of the European Parliament and of the Council of 30 November 2009 on cosmetic products. OJ. European Union 342. 59-209.

EU, 2009c. Regulation (EC) No 1272/2008 of the European Parliament and of the Council of 16 December 2008 on classification, labelling and packaging of substances and mixtures, amending and repealing Directives 67/548/EEC and 1999/45/EC, and amending Regulation (EC) No 1907/2006. OJ. European Union L353, 1-1355.

EU, 2010a. Directive 2010/63/EU of the European Parliament and of the Council of 22 September 2010 on the protection of animals used for scientific purposes. OJ. European Union L276, 34-79.

EU, 2010b. Directive 2010/75/EU of the European Parliament and of the Council of 24 November 2010 on industrial emissions (integrated pollution prevention and control) (Recast) L334, 17-119.

EU, 2010c. Sixth report on the statistics on the number of animals used for experimental and other scientific purposes in the member states of the European Union. SEC, p. 1107. Available at http://eur-lex.europa.eu.

$\mathrm{EU}, 2012$. Commission Communication in the framework of the implementation of Commission Regulation (EU) No 544/2011 as regards the requirements for the dossier to be submitted for the approval of an active substance. SANCO 11844/ 2010.

EU, 2012. Commission Communication in the framework of the implementation of Commission Regulation (EU) No 545/2011 laying down the requirements for the dossier to be submitted for the authorisation of plant protection products SANCO/11843/2010 Rev. 1 (POOL/E3/2010/11843/11843R1-EN.doc).

EU, 2012c. Regulation (EU) No 528/2012 of the European Parliament and of the Council of 22 May 2012 concerning the making available on the market and use of biocidal products. OJ. European Union L761, 1-123.

EU, 2013. Commission Regulation (EU) No 283/2013 of 1 March 2013 setting out the data requirements for active substances, in accordance with Regulation (EC) No 1107/2009 of the European Parliament and of the Council concerning the placing of plant protection products on the market. OJ. European Union L93, 184.

Federal Law Gazette, 2005. Volume 2005 Part I No. 5, published in Bonn On 01.25.2005. Announcement of the amendment of the Wastewater Charges Act on the 18th January 2005 (Bundesgesetzblatt (2005). Jahrgang 2005 Teil I Nr. 5 , ausgegeben zu Bonn am 25.01.2005. Bekanntmachung der Neufassung des Abwasserabgabengesetzes vom 18. Januar 2005).

Ferrari, T., Cattaneo, D., Gini, G., Golbamaki Bakhtyari, N., Manganaro, A., Benfenati, E., 2013. Automatic knowledge extraction from chemical structures: the case of mutagenicity prediction. SAR QSAR Environ. Res. 24, 365-383. 
Fini, J.B., Mével, S.L., Palmier, K., Darras, V.M., Punzon, I., Richardson, S.J., ClergetFroidevaux, M.S., Demeneix, B.A., 2012. Thyroid hormone signaling in the Xenopus laevis embryo is functional and susceptible to endocrine disruption. Endocrinology 153, 5068-5081.

Fischer, S., Klüver, N., Burkhardt-Medicke, K., Pietsch, M., Schmidt, A.-M., Wellner, P., Schirmer, K., Luckenbach, T., 2013. Abcb4 acts as multixenobiotic transporter and active barrier against chemical uptake in zebrafish (Danio rerio) embryos. BMC Biol. 11, 69.

Fischer, S., Loncar, J., Zaja, R., Schnell, S., Schirmer, K., Smital, T., Luckenbach, T. 2011. Constitutive mRNA expression and protein activity levels of nine ABC efflux transporters in seven permanent cell lines derived from different tissues of rainbow trout (Oncorhynchus mykiss). Aquat. Toxicol. 101, 438-446.

Foekema, E.M., Fischer, A., Parron, M.L., Kwadijk, C., de Vries, P., Murk, A.J., 2012. Toxic concentrations in fish early life stages peak at a critical moment. Environ. Toxicol. Chem. 31, 1381-1390.

Freyberger, A., Witters, H., Weimer, M., Lofink, W., Berckmans, P., Ahr, H.J., 2010. Screening for (anti) androgenic properties using a standard operation protocol based on the human stably transfected androgen sensitive PALM cell line. First steps towards validation. Reprod. Toxicol. 30, 9-17.

GAO, 2007. United States Government Accountability Office: Chemical regulation comparison of U.S. and recently enacted European Union approaches to protect against the risks of toxic chemicals. August 2007. GAO-07-825. Available at http://www.gao.gov.

Gobas, F.A.P.C., de Wolf, W., Burkhard, L.P., Verbruggen, E., Plotzke, K., 2009. Revisiting bioaccumulation criteria for POPs and PBT assessments. Integr. Environ. Assess. Manag. 5, 624-637.

Goldstone, J., McArthur, A., Kubota, A., Zanette, J., Parente, T., Jonsson, M., Nelson, D. Stegeman, J., 2010. Identification and developmental expression of the ful complement of Cytochrome P450 genes in Zebrafish. BMC Genom. 11, 643.

González-Doncel, M., Segundo, L.S., Sastre, S., Tarazona, J.V., Torija, C.F., 2011. Dynamics of BNF-induced in vivo ethoxyresorufin-O-deethylase (EROD) activity during embryonic development of medaka (Oryzias latipes). Aquat. Toxicol. $105,421-427$.

Grindon, C., Combes, R., Cronin, M.T.D., Roberts, D.W., Garrod, J., 2006. Integrated decision-tree testing strategies for environmental toxicity with respect to the requirements of the EU REACH legislation. ATLA 34, 651-664.

Gross, M., Daginnus, K., Deviller, G., de Wolf, W., Dungey, S., Galli, C., Gourmelon, A., Jacobs, M., Matthiessen, P., Micheletti, C., 2010. Thresholds of toxicological concern for endocrine active substances in the aquatic environment. Integr. Environ. Assess. Manag. 6, 2-11.

Gunnarsson, L., Jauhiainen, A., Kristiansson, E., Nerman, O., Larsson, D.G.J., 2008. Evolutionary conservation of human drug targets in organisms used for environmental risk assessments. Environ. Sci. Technol. 42, 5807-5813.

Hamers, T., Kamstra, J.H., Sonneveld, E., Murk, A.J., Visser, T.J., Van Velzen, M.J.M., Brouwer, A., Bergman, Å., 2008. Biotransformation of brominated flame retardants into potentially endocrine-disrupting metabolites, with special attention to 2,2',4,4'-tetrabromodiphenyl ether (BDE-47). Mol. Nutr. Food Res. $52,284-298$

Hardy, B., Douglas, N., Helma, C., Rautenberg, M., Jeliazkova, N., Jeliazkov, V., Nikolova, I., Benigni, R., Tcheremenskaia, O., Kramer, S., 2010. Collaborative development of predictive toxicology applications. J. Cheminform. 2, 1-29.

Hartung, T., Bremer, S., Casati, S., Coecke, S., Corvi, R., Fortaner, S., Gribaldo, L., Halder, M., Hoffmann, S., Roi, A.J., 2004. A modular approach to the ECVAM principles on test validity. ATLA 32, 467-472.

Hartung, T., Hoffmann, S., Stephens, M., 2013a. Food for thought... mechanistic validation. ALTEX 30, 119-130.

Hartung, T., Luechtefeld, T., Maertens, A., Kleensang, A., 2013b. Integrated testing strategies for safety assessments. ALTEX 30, 3-18.

Hartung, T., Rovida, C., 2009. Chemical regulators have overreached. Nature 460 1080-1081.

Hennes, E.C., 2012. An overview of values for the threshold of toxicological concern. Toxicol. Lett. 211, 296-303.

Hewitt, M., Ellison, C.M., 2010. Developing the applicability domain of In silico models: relevance, importance and methods. In: Cronin, M.T.D., Madden, J.C. (Eds.), In Silico Toxicology: Principles and Applications. The Royal Society of Chemistry, Cambridge, pp. 301-333.

Hoeger, B., Jeram, S., Holt, M., Douben, P., Halder, M., 2006. Reduction of animal use in acute aquatic toxicity testing: Further development of the threshold approach and its application to existing chemicals and plant protection products. Poster presentation at SETAC Europe 16th Annual Meeting 7-11 May 2006, abstract no MO1/AM/P05

Hoekzema, C.C., Murk, A.J., van de Waart, B.J., van der Hoeven, J.C.M., de Roode, D.F. 2006. Alternative approaches can greatly reduce the number of fish used for acute toxicity testing. Environ. Toxicol. Chem. 25, 1322-1325.

Hrovat, M., Segner, H., Jeram, S., 2009. Variability of in vivo fish acute toxicity data. Regul. Toxicol. Pharmacol. 54, 294-300.

Huggett, D.B., Cook, J.C., Ericson, J.F., Williams, R.T., 2003. A theoretical model for utilizing mammalian pharmacology and safety data to prioritize potential impacts of human pharmaceuticals to fish. Hum. Ecol. Risk Assess. 9, 17891799.

Hutchinson, T.H., Barrett, S., Buzby, M., Constable, D., Hartmann, A., Hayes, E. Huggett, D., Laenge, R., Lillicrap, A.D., Straub, J.O., Thompson, R.S., 2003. A strategy to reduce the numbers of fish used in acute ecotoxicity testing of pharmaceuticals. Environ. Toxicol. Chem. 22, 3031-3036.

IBAMA, 1996. Brazilian Institute of Environment and Renewable Natural resources, IBAMA regulation No 84, from October 15, 1996.
ISO 15088, 2007. Water quality - determination of the acute toxicity of waste water to zebrafish eggs (Danio rerio). ISO 15088:2007 (E).

Jager, T., 2012. Bad habits die hard: The NOEC's persistence reflects poorly on ecotoxicology. Environ. Toxicol. Chem. 31, 228-229.

Jeram, S., Sintes, J.M.R., Halder, M., Fentanes, J.B., Sokull-Klüttgen, B., Hutchinson, T.H., 2005. A strategy to reduce the use of fish in acute ecotoxicity testing of new chemical substances notified in the European Union. Regul. Toxicol. Pharmacol. 42, 218-224.

Ji, C., Jin, X., He, J., Yin, Z., 2012. Use of TSHbeta:EGFP transgenic zebrafish as a rapid in vivo model for assessing thyroid-disrupting chemicals. Toxicol. Appl. Pharmacol. 262, 149-155.

Johanning, K. Hancock, G., Escher, B., Adekola, A., Bernhard, M.J., CowanEllsberry, C., Domoradzki, J., Dyer, S., Eickhoff, C., Embry, M., Erhardt, S., Fitzsimmons, P., Halder, M., Hill, J., Holden, D., Johnson, R., Rutishauser, S., Segner, H., Schultz, I., Nichols, J., 2001. Assessment of metabolic stability using the rainbow trout (Oncorhynchus mykiss) liver S9 fraction. Curr. Protocols Toxicol., 1-28.

Jones, S.P., Kennedy, S.W., 2009. Chicken embryo cardiomyocyte cultures-a new approach for studying effects of halogenated aromatic hydrocarbons in the avian heart. Toxicol. Sci. 109, 66-74.

Judson, R.S., Martin, M.T., Reif, D.M., Houck, K.A., Knudsen, T.B., Rotroff, D.M., Xia, M., Sakamuru, S., Huang, R., Shinn, P., Austin, C.P., Kavlock, R.J., Dix, D.J., 2010. Analysis of eight oil spill dispersants using rapid, in vitro tests for endocrine and other biological activity. Environ. Sci. Technol. 44, 5979-5985.

Kaiser, K.L.E., Dearden, C.J., Klein, W., Schultz, T.W., 1999. A note of caution to users of ECOSAR. Water Qual. Res. J. Can. 34, 179-182.

Kavlock, R.J., Dix, D.J., Houck, K.A., Judson, R.S., Martin, M.T., Richard, A.M., 2007. ToxCastTM: Developing predictive signatures for chemical toxicity. AATEX 14, 623-627.

Kenaga, E.E., 1982. Predictability of chronic toxicity from acute toxicity of chemicals in fish and aquatic invertebrates. Environ. Toxicol. Chem. 1, 347-358.

Knacker, T., Boettcher, M., Frische, T., Rufli, H., Stolzenberg, H.-C., Teigeler, M., Zok, S., Braunbeck, T., Schäfers, C., 2010. Environmental effect assessment for sexual endocrine-disrupting chemicals: fish testing strategy. Integr. Environ. Assess. Manag. 6, 653-662.

Knöbel, M., Busser, F., Rico Rico, A., Kramer, N.I., Hermens, J.L.M., Hafner, C., Tanneberger, K., Schirmer, K., Scholz, S., 2012. Predicting adult fish acute lethality with the zebrafish embryo: relevance of test duration, endpoints, compound properties and exposure concentration analysis. Environ. Sci. Technol. 46, 9690-9700.

Koëter, H.B.W.M., 2003. Mutual acceptance of data: harmonised test methods and quality assurance of data-the process explained. Toxicol. Lett. 140, $11-20$.

Kohonen, P., Benfenati, E., Bower, D., Ceder, R., Crump, M., Cross, K., Grafström, R.C., Healy, L., Helma, C., Jeliazkova, N., 2013. The ToxBank Data Warehouse: supporting the replacement of in vivo repeated dose systemic toxicity testing. Mol. Inform. 32, 47-63.

Kokel, D., Bryan, J., Laggner, C., White, R., Cheung, C.Y.J., Mateus, R., Healey, D., Kim, S., Werdich, A.A., Haggarty, S.J., MacRae, C.A., Shoichet, B., Peterson, R.T., 2010. Rapid behavior-based identification of neuroactive small molecules in the zebrafish. Nat. Chem. Biol. 6, 231-237.

Kortenkamp, A., Backhaus, T., Faust, M., 2009. State of the Art Report on Mixture Toxicity. Report for Directorate General for the Environment of the European Commission, contract No. 070307/2007/485103/ETU/D.1. Available at htttp:// ec.europa.eu.

Kramer, N.I., Busser, F.J.M., Oosterwijk, M.T.T., Schirmer, K., Escher, B.I., Hermens, J.L.M., 2010. Development of a partition-controlled dosing system for cell assays. Chem. Res. Toxicol. 23, 1806-1814.

Kramer, N.I., Hermens, J.L.M., Schirmer, K., 2009. The influence of modes of action and physicochemical properties of chemicals on the correlation between in vitro and acute fish toxicity data. Toxicol. In vitro 23, 1372-1379.

Kramer, V.J., Etterson, M.A., Hecker, M., Murphy, C.A., Roesijadi, G., Spade, D.J., Spromberg, J.A., Wang, M., Ankley, G.T., 2011. Adverse Outcome Pathways and ecological risk assessment bridging to population-level effects. Environ. Toxicol. Chem. 30, 64-76.

Kroes, R., Kleiner, J., Renwick, A., 2005. The threshold of toxicological concern concept in risk assessment. Toxicol. Sci. 86, 226-230.

Kroes, R., Renwick, A.G., Cheeseman, M., Kleiner, J., Mangelsdorf, I., Piersma, A., Schilter, B., Schlatter, J., Van Schothorst, F., Vos, J.G., 2004. Structure-based thresholds of toxicological concern (TTC): guidance for application to substances present at low levels in the diet. Food Chem. Toxicol. 42, 65-83.

Kühne, R., Ebert, R.-U., Schüürmann, G., 2009. Chemical domain of QSAR models from atom-centered fragments. J. Chem. Inf. Model. 49, 2660-2669.

Kühnert, A., Vogs, C., Altenburger, R., Küster, E., 2013. The internal concentration of organic substances in fish embryos - a toxicokinetic approach. Environ. Toxicol. Chem. 32, 1819-1827.

Lammer, E., Carr, G.J., Wendler, K., Rawlings, J.M., Belanger, S.E., Braunbeck, T., 2009a. Is the fish embryo toxicity test (FET) with the zebrafish (Danio rerio) a potential alternative for the fish acute toxicity test? Comp. Biochem. Phys. C. 149, 196-209.

Lammer, E., Kamp, H.G., Hisgen, V., Koch, M., Reinhard, D., Salinas, E.R., Wendler, K., Zok, S., Braunbeck, T., 2009b. Development of a flow-through system for the fish embryo toxicity test (FET) with the zebrafish (Danio rerio). Toxicol. In vitro 23 , $1436-1442$

Landis, W.G., Chapman, P.M., 2011. Well past time to stop using NOELs and LOELs. Integr. Environ. Assess. Manag. 7, vi-viii. 
Leist, M., Hasiwa, N., Daneshian, M., Hartung, T., 2012. Validation and quality control of replacement alternatives - current status and future challenges. Toxicol. Res..

McElroy, K., Kardisch, J.H., Ortego, J.J., 2011. Federal insecticide, fungicide and rodenticide act: preemption and toxic tort law. Fordham Environ. Law Rev. 2, 29.

McGrath, J.A., Di Toro, D.M., 2009. Validation of the target lipid model for toxicity assessment of residual petroleum constituents: monocyclic and polycyclic aromatic hydrocarbons. Environ. Toxicol. Chem. 28, 1130-1148.

Montaño, M., Cocco, E., Guignard, C., Marsh, G., Hoffmann, L., Bergman, Å., Gutleb, A.C., Murk, A.J., 2012. New approaches to assess the transthyretin binding capacity of bioactivated thyroid hormone disruptors. Toxcol. Sci. 130, 94-105, \%R 10.1093/toxsci/kfs228.

Mulliner, D., Wondrousch, D., Schuurmann, G., 2011. Predicting Michael-acceptor reactivity and toxicity through quantum chemical transition-state calculations. Org. Biomol. Chem. 9, 8400-8412.

Munn, S., Goumenou, M., 2013. Key scientific issues relevant to the identification and characterisation of endocrine disrupting substances. Report of the Endocrine Disrupters Expert Advisory Group. European Commission, JRC Scientific and Policy Reports. Report EUR 25919 EN. ISBN 978-92-79-29371-9. Available at http://ihcp.jrc.ec.europa.eu.

Murk, A.J., Rijntjes, E., Blaauboer, B.J., Clewell, R., Crofton, K.M., Dingemans, M.M., Furlow, J.D., Kavlock, R., Kohrle, J., Opitz, R., Traas, T., Visser, T.J., Xia, M., Gutleb, A.C., 2013. Mechanism-based testing strategy using in vitro approaches for identification of thyroid hormone disrupting chemicals. Toxicol. In vitro 27 , $1320-1346$.

Nagel, R., 2002. DarT: the embryotest with the zebrafish Danio rerio - a general model in ecotoxicology and toxicology. Alternativen zu Tierexperimenten 19 (Suppl. 1/02), 38-48.

Naturvårdsverket, 2010. Kemisk och biologisk karakterisering av punktutsläpp till vatten. Available at http://www.naturvardsverket.se.

Netzeva, T.I., Worth, A.P., Aldenberg, T., Benigni, R., Cronin, M.T.D., Gramatica, P., Jaworska, J.S., Kahn, S., Klopman, G., Marchant, C.A., 2005. Current status of methods for defining the applicability domain of (quantitative) structureactivity relationships. ATLA 33, 1-19.

Nichols, J.W., Huggett, D.B., Arnot, J.A., Fitzsimmons, P.N., Cowan-Ellsberry, C.E., 2013. Toward improved models for predicting bioconcentration of wellmetabolized compounds by rainbow trout using measured rates of in vitro intrinsic clearance. Environ. Toxicol. Chem. 32, 1611-1622.

Nichols, J.W., Schultz, I.R., Fitzsimmons, P.N., 2006. In vitro-in vivo extrapolation of quantitative hepatic biotransformation data for fish: I. A review of methods, and strategies for incorporating intrinsic clearance estimates into chemical kinetic models. Aquat. Toxicol. 78, 74-90.

Noury, P., Geffard, O., Tutundjian, R., Garric, J., 2006. Non destructive in vivo measurement of ethoxyresorufin biotransformation by zebrafish prolarva: development and application. Environ. Toxicol. 21, 324-331.

OECD, 1984. OECD guideline for testing of chemical. Test No. 206 - Avian reproduction test. Available at http://www.oecd-library.org.

OECD, 1992. OECD guideline for testing of chemicals. Test No. 203: acute fish test. Available at http://www.oecd.org.

OECD, 1996. Report of the OECD workshop on "Harmonisation of Validation and Acceptance Criteria for Alternative Toxicological Test Methods” (Solna Report). OECD, Paris, 60 pp. (ENV/MC/CHEM(96)9).

OECD, 2005. Guidance document on the validation and international acceptance of new or updated test methods for hazard assessment. OECD Series on Testing and Assessment No. 34, 96 pp. (ENV/JM/MONO(2005)14).

$\mathrm{OECD}, 2007$. Guidance document on the validation of (quantitative) structureactivity relationships [(Q)SAR] models. 154 pp. Available at http:// www.oecd.org (ENV/JM/MONO(2007)2).

OECD, 2007. Series on testing and assessment. Number 80. Guidance on grouping of chemicals. 99 pp. Available at http://www.oecd.org (ENV/JM/MONO(2007)28).

OECD, 2009. OECD guideline 456 for the testing of chemicals - The H295R Steroidogenesis Assay. Available from http://www.oedc.org.

OECD, 2009. TG 455. Stably transfected human estrogen receptor- $\alpha$ transcriptional activation assay for detection of estrogenic agonist-activity of chenmicals. Available at http://www.oecd.org.

OECD, 2010. TG 126. Short guidance on the Threshold Approach for acute fish toxicity. Available at http://www.oecd.org (ENV/JM/TG(2010)/7).

OECD, 2012. The Adverse Outcome Pathway for Skin Sensitisation Initiated by Covalent Binding to Proteins. Part 1: Scientific Evidence. Series on Testing and Assessment No.168. Available at http://search.oecd.org.

OECD, 2012. Fish toxicity testing framework. Series on Testing and Assessment. No. 171. Available at http://www.oecd.org.

OECD, 2012. Guidelines for the testing of chemicals. TG 443: Extended OneGeneration Reproductive Toxicity Study. Available at http://www.oecdlibrary.org.

OECD, 2012. Information on OECD work related to endocrine disrupters. Available at http://www.oecd.org.

OECD, 2012. Proposal for a template, and guidance on developing and assessing the completeness of adverse outcome pathways. Available at http://www.oecd.org.

OECD, 2012. TG 305. Bioaccumulation in Fish: Aqueous and Dietary Exposure. Available at http://www.oecd.org.

OECD, 2012. Validation report (phase 2) for the zebrafish embryo toxicity test. Series on Testing and Assessment No. 179. Available at http://www.oecd.org.

OECD, 2013. OECD 236 - Draft Guideline for the Testing of Chemicals: Fish Embryo Acute Toxicity Test, approved by WNT25. Available at http://www.oecd.org.
Opitz, R., Maquet, E., Huisken, J., Antonica, F., Trubiroha, A., Pottier, G., Janssens, V. Costagliola, S., 2012. Transgenic zebrafish illuminate the dynamics of thyroid morphogenesis and its relationship to cardiovascular development. Dev. Biol. 372, 203-216.

Oris, J.T., Belanger, S.E., Bailer, A.J., 2012. Baseline characteristics and statistical implications for the OECD 210 fish early life stage chronic toxicity test. Environ. Toxicol. Chem. 31, 370-376.

OSIRIS, 2011. Optimized strategies for risk assessment of industrial chemicals through integration of non-test and test information. EU project, contract no. GOCE-CT-2007-037017, 2007-2011. OSIRIS project website: http://www.osirisreach.eu. OSIRIS web-tool website: http://osiris.simpple.com/OSIRIS-ITS/ welcome.do.

OSPAR, 2000. (Convention for the Protection of the Marine Environment of the North-East Atlantic) Background document concerning the elaboration of programmes and measures relating to whole effluent assessment (Report 117; London: OSPAR).

OSPAR, 2007. Practical guidance document on whole effluent assessment. OSPAR Hazardous Substances Committee (HSC). Available at http://www.ospar.org.

OSPAR, 2012. OSPAR guidelines for completing the harmonised offshore chemical notification format (HOCNF). Available at http://www.ofsar.org.

Parkerton, T., Rauert, C., Huggett, D., Woodburn, K., Nichols, J., Lillicrap, A., Embry M., 2012. Experts review advances in bioaccumulation science and identify future priorities. SETAC Globe. 13. Available at http://ww2.setac.org/globe/ 2012/october/experts-review.html.

Parkerton, T.F., Arnot, J.A., Weisbrod, A.V., Russom, C., Hoke, R.A., Woodburn, K. Traas, T., Bonnell, M., Burkhard, L.P., Lampi, M.A., 2008. Guidance for evaluating in vivo fish bioaccumulation data. Integr. Environ. Assess. Manag. 4, 139-155.

Porte, C., Janer, G., Lorusso, L.C., Ortiz-Zarragoitia, M., Cajaraville, M.P., Fossi, M.C. Canesi, L., 2006. Endocrine disruptors in marine organisms: Approaches and perspectives. Comp. Biochem. Phys. C 143, 303-315.

Punt, A., Brand, W., Murk, A.J., van Wezel, A.P., Schriks, M., Heringa, M.B., 2013 Effect of combining in vitro estrogenicity data with kinetic characteristics of estrogenic compounds on the in vivo predictive value. Toxicol. In Vitro 27, 4451.

Raimondo, S., Montague, B.J., Barron, M.G., 2007. Determinants of variability in acute to chronic toxicity ratios for aquatic invertebrates and fish. Environ. Toxicol. Chem., 2019-2023.

Ravindra, P.K.V., Chauhan, R.S., Girish, P.K.V., 2006. Use of avian lymphocytes to detect toxicity: effects of a commonly utilized deltamethrin preparation. J. Immunotoxicol. 3, 101-109.

Redman, A.D., Parkerton, T.F., McGrath, J.A., Di Toro, D.M., 2012. PETROTOX: an aquatic toxicity model for petroleum substances. Environ. Toxicol. Chem. 31 2498-2506.

Riedl, J., Altenburger, R., 2007. Physicochemical substance properties as indicators for unreliable exposure in microplate-based bioassays. Chemosphere 67, 2210 2220.

Robinson, S., Delongeas, J., Donald, E., Dreher, D., Festag, M., Kervyn, S., Lampo, A., Nahas, K., Nogues, V., Ockert, D., 2008. A European pharmaceutical company initiative challenging the regulatory requirement for acute toxicity studies in pharmaceutical drug development. Regul. Toxicol. Pharmacol. 50, 345-352.

Rorije, E., Aldenberg, T., Buist, H., Kroese, D., Schüürmann, G., 2013. The OSIRIS weight of evidence approach: ITS for skin sensitisation. Regul. Toxicol. Pharmacol. 67, 146-156.

Rufli, H., Springer, T.A., 2011. Can we reduce the number of fish in the OECD acute toxicity test? Environ. Toxicol. Chem. 30, 1006-1011.

Russell, W., Burch, R., 1959. The Principles of Humane Experimental Technique. Methuen, London.

Russom, C.L., Bradbury, S.P., Broderius, S.J., Hammermeister, D.E., Drummond, R.A 1997. Predicting modes of toxic action from chemical structure: acute toxicity in the fathead minnow (Pimephales promelas). Environ. Toxicol. Chem. 16, 948967.

Sand, S., von Rosen, D., Victorin, K., Falk Filipsson, A., 2006. Identification of a critical dose level for risk assessment: developments in benchmark dose analysis of continuous endpoints. Toxicol. Sci. 90, 241-251.

Schirmer, K., 2006. Proposal to improve vertebrate cell cultures to establish them as substitutes for the regulatory testing of chemicals and effluents using fish. Toxicology 224, 163-183.

Schirmer, K., Chan, A.G.J., Greenberg, B.M., Dixon, D.G., Bols, N.C., 1997 Methodology for demonstrating and measuring the photocytotoxicity of fluoranthene to fish cells in culture. Toxicol. In vitro 11, 107-119.

Schirmer, K., Fischer, B., Madureira, D., Pillai, S., 2010. Transcriptomics in ecotoxicology. Anal. Bioanal. Chem. 397, 917-923.

Schmidt, C., 2009. Tox21: new dimensions of toxicity testing tox21: new dimensions of toxicity testing. Environ. Health Perspect. 117, A348-A353.

Scholz, S., Renner, P., Belanger, S., Busquet, F., Davi, R., Demeneix, B., Denny, J., Leonard, M., McMaster, M., Villeneuve, D., Embry, M., 2013. Alternatives to in vivo tests to detect endocrine disrupting chemicals (EDCs) in fish and amphibians - screening for estrogen, androgen and thyroid hormone disruption. CRC Cr. Rev. Toxicol. 43, 45-72.

Scholz, S., Schirmer, K., Altenburger, R., 2010. Pharmaceutical contaminants in urban water cycles - a discussion of novel concepts for environmental risk assessment. In: Kassinos, F., Bester, K., Kümmerer, K. (Eds.), Xenobiotics in the Urban Water Cycle: Mass Flows, Environmental Processes and Mitigation Strategies. Springer, Heidelberg, pp. 227-243.

Schramm, F., Müller, A., Hammer, H., Paschke, A., Schüürmann, G., 2011. Epoxide and thiirane toxicity in vitro with the ciliate Tetrahymena pyriformis 
structural alerts indicating excess toxicity. Environ. Sci. Technol. 45, 58125819.

Schreiber, R., Altenburger, R., Paschke, A., Küster, E., 2008. How to deal with lipophilic and volatile organic substances in microtiter plate assays. Environ. Toxicol. Chem. 27, 1676-1682.

Schreiber, R., Altenburger, R., Paschke, A., Schüürmann, G., Küster, E., 2009. A novel in vitro system for the determination of bioconcentration factors and the internal dose in zebrafish (Danio rerio) eggs. Chemosphere 77 , 928-933.

Schreiber, R., Gündel, U., Franz, S., Küster, A., Rechenberg, B., Altenburger, R., 2011. Using the fish plasma model for comparative hazard identification for pharmaceuticals in the environment by extrapolation from human therapeutic data. Regul. Toxicol. Pharmacol. 61, 261-275.

Schüürmann, G., Ebert, R.-U., Kühne, R., 2011. Quantitative read-across for predicting the acute fish toxicity of organic compounds. Environ. Sci. Technol. 45, 4616-4622.

Schüürmann, G., Ebert, R.U., Nendza, M., Dearden, J.C., Paschke, A., Kühne, R., 2007. Predicting fate-related physicochemical properties. In: Van Leeuwen, K. Vermeire, T. (Eds.), Risk Assessment of Chemicals: An Introduction. Springer, Dordrecht, The Netherlands, pp. 375-426.

Schüürmann, G., Kühne, R., Kleint, F., Ebert, R.U., Rothenbacher, C., Herth, P., 1997. A software system for automatic chemical property estimation from molecular structure. In: Chen, F., Schüürmann, G. (Eds.), Quantitative structure activity relationship in environmental sciences - VII. SETAC Press, Pensacola, FL, pp. 93114.

Schwöbel, J.A.H., Wondrousch, D., Koleva, Y.K., Madden, J.C., Cronin, M.T.D. Schüürmann, G., 2010. Prediction of Michael-type acceptor reactivity toward glutathione. Chem. Res. Toxicol. 23, 1576-1585.

Seidle, T., Robinson, S., Holmes, T., Creton, S., Prieto, P., Scheel, J., Chlebus, M., 2010 Cross-sector review of drivers and available 3Rs approaches for acute systemic toxicity testing. Toxicol. Sci. 116, 382-396.

Selderslaghs, I.W.T., Hooyberghs, J., Blust, R., Witters, H.E., 2013. Assessment of the developmental neurotoxicity of compounds by measuring locomotor activity in zebrafish embryos and larvae. Neurotoxicol. Teratol. 37, 44-56.

Smith, K.E.C., Dom, N., Blust, R., Mayer, P., 2010. Controlling and maintaining exposure of hydrophobic organic compounds in aquatic toxicity tests by passive dosing. Aquat. Toxicol. 98, 15-24.

Smith, K.E.C., Oostingh, G.J., Mayer, P., 2009. Passive dosing for producing defined and constant exposure of hydrophobic organic compounds during in vitro toxicity tests. Chem. Res. Toxicol. 23, 55-65.

Spielmann, H., Sauer, U.G., Mekenyan, O., 2011. A critical evaluation of the 2011 ECHA reports on compliance with the REACH and CLP regulations and on the use of alternatives to testing on animals for compliance with the REACH regulation. ATLA 39, 481-493.

Spielmann, H., Vogel, R., 2007. The extended 1-generation study (OECD 415), as a replacement of the mammalian 2-generation study (OECD 416). AATEX 14 795-798.

Sun, H., Xia, M., Austin, C.P., Huang, R., 2012. Paradigm shift in toxicity testing and modeling. AAPS J. 14, 473-480.

Sunderam, R.M., Patra, R.W., Julli, M., Warne, M.S.J., 2004. Use of the Up-and-Down acute toxicity test procedure to generate $\mathrm{LC}_{50}$ data for fish. Bull. Environ. Contam. Toxicol. 72, 873-880.

Tanneberger, K., Knöbel, M., Busser, F.J., Sinnige, T.L., Hermens, J.L., Schirmer, K., 2013. Predicting fish acute toxicity using a fish gill cell line-based toxicity assay Environ. Sci. Technol. 47, 1110-1119.

Tanneberger, K., Rico-Rico, A., Kramer, N.I., Busser, F.J.M., Hermens, J.L.M., Schirmer K., 2010. Effects of solvents and dosing procedure on chemical toxicity in cellbased in vitro assays. Environ. Sci. Technol. 44, 4775-4781.

Thibaut, R., Schnell, S., Porte, C., 2009. Assessment of metabolic capabilities of PLHC1 and RTL-W1 fish liver cell lines. Cell Biol. Toxicol. 25, 611-622.

Thienpont, B., Tingaud-Sequeira, A., Prats, E., Barata, C., Babin, P.J., Raldua, D., 2011 Zebrafish eleutheroembryos provide a suitable vertebrate model for screening chemicals that impair thyroid hormone synthesis. Environ. Sci. Technol. 45, 7525-7532.

Tluczkiewicz, I., Batke, M., Kroese, D., Buist, H., Aldenberg, T., Pauné, E., Grimm, H., Kühne, R., Schüürmann, G., Mangelsdorf, I., Escher, S.E., 2013. The OSIRIS Weight of Evidence approach: ITS for the endpoints repeated-dose toxicity (RepDose ITS). Regul. Toxicol. Pharmacol. (in press).

UK Environment Agency, 2006. Integrated Pollution Prevention \& Control (IPPC) Guidance on the use of direct toxicity assessment in PPC impact assessments. 44 p. Available at http://publications.environment-agency.gov.uk.

UN, 2011. United Nations, New York and Geneva: Globally harmonized system of classification and labelling of chemicals (GSH). Fourth revised edition. Available at http://www.unece.org.

UNEP, 2012. United Nations Environment Programme and World Health Organization: State of the science of endocrine disrupting chemicals - 2012 Available at http://unep.org.

US congress, 2002. Federal, food, drug and cosmetic act. Available at http:/ epw.senate.gov.

US EPA, 1996. Ecological Effects Test Guidelines: OPPTS 850.1075 - Fish Acute Toxicity Test, Freshwater and Marine. Available at http://www.epa.gov.

US EPA, 1996. Ecological Effects Test Guidelines: OPPTS 850.1500 - Fish life cycle toxicity. EPA712-C-96-122. Available at http://www.epa.gov.

US EPA, 1998. User's guide for conducting life-cycle chronic toxicity tests with fathead minnows (Pimephales promelas). EPA-600/8-81-011. Available at http://nepis.epa.gov.
US EPA, 2002. Methods for measuring the acute toxicity of effluents and receiving water to freshwater and marine organisms, fifth ed. EPA-821-R-02-012. Available at http://nepis.epa.gov.

US EPA, 2004. Draft detailed review paper for Amphibian Growth and Reproduction Assay (tier 2), EPA contract number 68-W-01-023, work assignment 4-8. Available at http://www.epa.gov.

US EPA, 2005. Pollution Prevention (P2) Framework Manual, US Environmental Protection Agency, OPPT, EPA-748-B-04-001. Available at http://www.epa.gov.

US EPA, 2009. Endocrine disruptor screening program test guidelines. OPPTS 890.1350: Fish short-term reproduction assay. Available at http:// www.epa.gov.

US EPA, 2011. Endocrine disruptor screening program for the 21st century (EDSP21 work plan): the incorporation of in silico models and in vitro high throughput assays in the endocrine disruptor screening program (EDSP) for prioritization and screening. Available at http://www.epa.gov.

US EPA, 2012. Ecological Effects Test Guidelines: OCSPP 850.2300 - Avian reproduction test. EPA 712-C-023. Available at http:// www.regulations.gov.

US EPA, 2013. Estimation Programs Interface Suite ${ }^{\mathrm{TM}}$ for Microsoft ${ }^{\circledR}$ Windows, v 4.11. United States Environmental Protection Agency, Washington, DC, USA. Available at http://www.epa.gov.

US FDA, 1998. Guidance for industry - environmental assessment of human drug and biologics applications. US Department of Health and Human Services, Food and Drug Administration, CMC6, revision 1. Food and Drug Administration. Available at http://www.fda.org.

Van den Brink, P.J., Blake, N., Brock, T.C.M., Maltby, L., 2006. Predictive value of species sensitivity distributions for effects of herbicides in freshwater ecosystems. Hum. Ecol. Risk Assess. 12, 645-674.

van der Jagt, K., Munn, S., Torslov, J., Bruijn, J.d., 2004. Alternative approaches can reduce the use of test animals under REACH. Addendum to the report: Assessment of additional testing needs under REACH - Effects of (Q)SARS, risk based testing and voluntary industry initiatives. Commission of the European Union. EUR 21405 EN.

Verhaar, H.J.M., Van Leeuwen, C.J., Hermens, J.L.M., 1992. Classifying environmental pollutants. 1: structure-activity relationships for prediction of aquatic toxicity. Chemosphere 25, 471-491.

Villeneuve, D., Volz, D., Embry, M., Ankley, G., Belanger, S., Léonard, M., Schirmer, K., Tanguay, R., Truong, L., Wehmas, L., 2013. Investigating alternatives to the fish early life-stage test: a strategy for discovering and annotating adverse outcome pathways for early fish development. Environ. Toxicol. Chem. (in press, http:// dx.doi.org/10.1002/etc.2403).

Villeneuve, D.L., Garcia-Reyero, N., 2011. Vision \& strategy: predictive ecotoxicology in the 21st century. Environ. Toxicol. Chem. 30, 1-8.

Voelker, D., Vess, C., Tillmann, M., Nagel, R., Otto, G.W., Geisler, R., Schirmer, K., Scholz, S., 2007. Differential gene expression as a toxicant-sensitive endpoint in zebrafish embryos and larvae. Aquat. Toxicol. 81, 355-364.

Volz, D.C., Belanger, S., Embry, M., Padilla, S., Sanderson, H., Schirmer, K., Scholz, S., Villeneuve, D., 2011. Adverse outcome pathways during early fish development: a conceptual framework for identification of chemical screening and prioritization strategies. Toxicol. Sci. 123, 349-358.

Von der Ohe, P.C., Kuhne, R., Ebert, R.-U., Altenburger, R., Liess, M., Schüürmann, G., 2005. Structural alerts - a new classification model to discriminate excess toxicity from narcotic effect levels of organic compounds in the acute daphnid assay. Chem. Res. Toxicol. 18, 536-555.

Vongphachan, V., Cassone, C.G., Wu, D., Chiu, S., Crump, D., Kennedy, S.W., 2011 Effects of perfluoroalkyl compounds on mRNA expression levels of thyroid hormone-responsive genes in primary cultures of avian neuronal cells. Toxicol. Sci. 120, 392-402

Weigt, S., Huebler, N., Braunbeck, T., von Landenberg, F., Broschard, T.H., 2010. Zebrafish teratogenicity test with metabolic activation (mDarT): effects of phase I activation of acetaminophen on zebrafish Danio rerio embryos. Toxicology 275, 36-49.

Weigt, S., Huebler, N., Strecker, R., Braunbeck, T., Broschard, T.H., 2011. Zebrafish (Danio rerio) embryos as a model for testing proteratogens. Toxicology 281, 2536.

Weigt, S., Huebler, N., Strecker, R., Braunbeck, T., Broschard, T.H., 2012. Developmental effects of coumarin and the anticoagulant coumarin derivative warfarin on zebrafish (Danio rerio) embryos. Reprod. Toxicol. 33, 133-141.

Weil, M., Sacher, F., Scholz, S., Zimmer, M., Duis, K., 2009. Gene expression analysis in zebrafish embryos: a potential approach to predict effect concentrations in the fish early life stage test. Environ. Toxicol. Chem. 28, 1970-1978.

Weisbrod, A.V., Sahi, J., Segner, H., James, M.O., Nichols, J., Schultz, I., Erhardt, S., Cowan-Ellsberry, C., Bonnell, M., Hoeger, B., 2009. The state of in vitro science for use in bioaccumulation assessments for fish. Environ. Toxicol. Chem., 86-96.

Weltje, L., Wheeler, J.R., Weyers, A., Galay-Burgos, M., 2013. Refinement of the ECETOC approach to identify endocrine disrupting properties of chemicals in ecotoxicology. Toxicol. Lett. (in press, http://dx.doi.org/10.1016/j.toxlet.2013. 02.019).

Wheeler, J.R., Panter, G.H., Weltje, L., Thorpe, K.L., 2013. Test concentration setting for fish in vivo endocrine screening assays. Chemosphere 92, 1067-1076.

Williams, E.S., Berninger, J.P., Brooks, B.W., 2011. Application of chemical toxicity distributions to ecotoxicology data requirements under REACH. Environ. Toxicol. Chem. 30, 1943-1954.

Witters, H., Freyberger, A., Smits, K., Vangenechten, C., Lofink, W., Weimer, M., Bremer, S., Ahr, P.-J., Berckmans, P., 2010. The assessment of estrogenic or anti- 
estrogenic activity of chemicals by the human stably transfected estrogen sensitive MELN cell line: results of test performance and transferability. Reprod. Toxicol. 30, 60-72.

Wittwehr, C., 2011. Neuer Zugang zu Chemikalien-Daten. eChemPortal. Chemie in unserer Zeit. 45, 122-125.

Worth, A.P., Bassan, A., De Bruijn, J., Saliner, A.G., Netzeva, T., Pavan, M., Patlewicz, G., Tsakovska, I., Eisenreich, S., 2007. The role of the European Chemicals Bureau in promoting the regulatory use of (Q) SAR methods. SAR QSAR Environ. Res. 18, 111-125.

Zvinavashe, E., Murk, A.J., Rietjens, I.M., 2008. Promises and pitfalls of quantitative structure-activity relationship approaches for predicting metabolism and toxicity. Chem. Res. Toxicol. 21, 2229-2236.

Zvinavashe, E., Murk, A.J., Rietjens, I.M., 2009. On the number of EINECS compounds that can be covered by (Q)SAR models for acute toxicity. Toxicol. Lett. 184, 67-72. 